\title{
Light Quality-Dependent Regulation of Non-Photochemical Quenching in Tomato Plants
}

\author{
Magdalena Trojak ${ }^{1, *(D)}$ and Ernest Skowron ${ }^{2}$ (D) \\ 1 Department of Medical Biology, Jan Kochanowski University, Uniwersytecka 7, 25-406 Kielce, Poland \\ 2 Department of Environmental Biology, Jan Kochanowski University, Uniwersytecka 7, 25-406 Kielce, Poland; \\ ernest.skowron@ujk.edu.pl \\ * Correspondence: magdalena.trojak@ujk.edu.pl; Tel.: +48-41-3496337
}

Citation: Trojak, M.; Skowron, E. Light Quality-Dependent Regulation of Non-Photochemical Quenching in Tomato Plants. Biology 2021, 10, 721. https://doi.org/10.3390/

biology10080721

Academic Editor: Fiorella Lo Schiavo

Received: 17 June 2021

Accepted: 26 July 2021

Published: 28 July 2021

Publisher's Note: MDPI stays neutral with regard to jurisdictional claims in published maps and institutional affiliations.

Copyright: (c) 2021 by the authors. Licensee MDPI, Basel, Switzerland. This article is an open access article distributed under the terms and conditions of the Creative Commons Attribution (CC BY) license (https:/ / creativecommons.org/licenses/by/ $4.0 /)$.
Simple Summary: Photosynthetic organisms, such as land plants, evolved to utilize available light and to use its energy to assimilate carbon dioxide and produce carbohydrates. However, the light intensity often exceeds the ability of plants to successfully utilize absorbed energy, thus inducing stress, manifested by an increased radical concentration inside plant cells and disruption of the inner structures, and consequently decreased plant yield. Plants solve this problem by using a mechanism termed non-photochemical quenching, by which they can dissipate the energy not used in photosynthesis. Modern agriculture, however, also involves indoor plant farming. For indoor plant farming LED-based lighting systems, with non-saturating light intensities, are suitable based on their restricted energy consumption. However, the composition of applied light should first be optimized to maximize its utilization. Our study examined the influence of monochromatic LEDs (red, green, and blue) on the photoprotective and photosynthetic properties of tomato plants. We indicate that monochromatic green light could be considered an important component of lighting systems to alleviate energy dissipation, while blue light enhances photosynthetic efficiency. Our study not only proves the crucial importance of spectrum optimization but also provides evidence that different light wavelengths modify photosynthetic and photoprotective properties.

Abstract: Photosynthetic pigments of plants capture light as a source of energy for photosynthesis. However, the amount of energy absorbed often exceeds its utilization, thus causing damage to the photosynthetic apparatus. Plants possess several mechanisms to minimize such risks, including non-photochemical quenching (NPQ), which allows them to dissipate excess excitation energy in the form of harmless heat. However, under non-stressful conditions in indoor farming, it would be favorable to restrict the NPQ activity and increase plant photosynthetic performance by optimizing the light spectrum. Towards this goal, we investigated the dynamics of NPQ, photosynthetic properties, and antioxidant activity in the leaves of tomato plants grown under different light qualities: monochromatic red (R), green (G), or blue (B) light (L) at $80 \mu \mathrm{mol} \mathrm{m}{ }^{-2} \mathrm{~s}^{-1}$ and $\mathrm{R}: \mathrm{G}: \mathrm{B}=1: 1: 1$ (referred to as the white light (WL)) at $120 \mu \mathrm{mol} \mathrm{m}{ }^{-2} \mathrm{~s}^{-1}$. The results confirm that monochromatic BL increased the quantum efficiency of PSII and photosynthetic pigments accumulation. The RL and BL treatments enhanced the NPQ amplitude and showed negative effects on antioxidant enzyme activity. In contrast, plants grown solely under GL or WL presented a lower amplitude of NPQ due to the reduced accumulation of NPQ-related proteins, photosystem II (PSII) subunit S (PsbS), PROTON GRADIENT REGULATION-LIKE1 (PGRL1), cytochrome $b_{6} f$ subunit $f$ (cyt $f$ ) and violaxanthin deepoxidase (VDE). Additionally, we noticed that plants grown under GL or RL presented an increased rate of lipid peroxidation. Overall, our results indicate the potential role of GL in lowering the NPQ amplitude, while the role of BL in the RGB spectrum is to ensure photosynthetic performance and photoprotective properties.

Keywords: antioxidant enzyme; chlorophyll fluorescence quenching; indoor farming; light quality; LED; non-photochemical quenching 


\section{Introduction}

The initial step of photosynthesis involves the absorption of light. However, when the amount of light absorbed exceeds the capacity of its photosynthetic utilization, this can lead to the formation of reactive oxygen species (ROS) and damage to the photosynthetic apparatus [1,2]. To reduce the risk of potential damage plants evolved protective mechanisms, including ways to minimize light absorption, detoxify ROS and dissipate excess light energy as heat [3]. This thermal dissipation process, called non-photochemical quenching (NPQ), acts as a safety valve. NPQ includes components with different mechanisms and characteristic times-energy-dependent (qE), zeaxanthin (Z)-dependent (qZ), and photoinhibitory (qI) — as well as components related to state transition (qT), chloroplast movement (qM) [4], and the newly termed plastid lipocalin-dependent photoprotective antenna quenching $(\mathrm{qH})$ [3]. Extensive research, devoted to understanding the mechanism of NPQ components might be justified, as NPQ has been considered to be a prime target to increase light use efficiency [5].

First, energy-dependent quenching, $\mathrm{qE}$, is turned on rapidly by an increase in thylakoid lumen proton concentration, followed by protonation of the thylakoid membrane protein, photosystem II (PSII) subunit S (PsbS) [6], and reversible conversion of xanthophyll pigments. $\mathrm{qE}$ follows the variations of the transmembrane proton gradient $(\Delta \mathrm{pH})$, thus its induction and relaxation typically develop within a few minutes $(1-3 \mathrm{~min})[7,8]$. For $\mathrm{qE}$, it is proposed that PsbS promotes energy quenching as it triggers the undocking of light-harvesting complex II (LHCII) from the PSII core [9], thus promoting antenna oligomerization. Protonation of PsbS is initiated by linear electron transport (LET) and cyclic electron transport (CET) coupled with the proton pumping activity of cytochrome $b_{6} f\left(\mathrm{cyt}_{6} f\right)[10]$.

Second, qZ, another NPQ component, is detectable within 10-15 min and is related to violaxanthin $(\mathrm{V})$ de-epoxidation [9] but not to PsbS [8]. Thus, the $\mathrm{qZ}$ component is strictly related to the xanthophyll cycle activity [11]. The drop in lumen $\mathrm{pH}$ activates violaxanthin de-epoxidase (VDE) and shifts the xanthophyll balance from $\mathrm{V}$ which acts as a light-harvesting pigment, toward $\mathrm{Z}$ favoring dissipation of the excitation energy through heat [12]. However, while $\mathrm{qE}$ relaxation is fully activated by the collapse of $\Delta \mathrm{pH}, \mathrm{qZ}$ relaxation is prolonged, and qZ NPQ appears to remain active even in the absence of a low lumen $\mathrm{pH}$ [13].

Third, the photoinhibitory component of NPQ, qI, is slowly reversible (within hours) and comprises processes related to either PSII core inactivation characterized by reduced maximal photochemical efficiency (Fv/Fm) [14] or slowly relaxing quenching, recently termed $\mathrm{qH}$ [3]. The $\mathrm{qT}$ component, which indicates state transitions, is triggered by low light conditions to balance the energy distribution of light energy between PSII and photosystem I (PSI) [15].

Moreover, previous research also proved, that the antioxidant capacity of plant cells interferes with NPQ activity [1] and both are related to spectrum quality [16,17]. The relationship between antioxidants and NPQ might be explained by considering the VDE enzyme, the domain of which has been suggested to bind the main substrate $\mathrm{V}$ and the co-substrate ascorbic acid (AsA) as a reductant [11,18]. This is because, AsA also has a photoprotective function as a cofactor for antioxidant enzymes, such as ascorbate peroxidase (APX) [1], in scavenging ROS. Photoreduction of oxygen by PSI to a superoxide anion radical is followed by its dismutation to hydrogen peroxide $\left(\mathrm{H}_{2} \mathrm{O}_{2}\right)$ and oxygen by superoxide dismutase (SOD). Then $\mathrm{H}_{2} \mathrm{O}_{2}$ is reduced by APX to water [1]. Like APX, catalase (CAT) also detoxifies $\mathrm{H}_{2} \mathrm{O}_{2}$; however, CAT mainly occurs in peroxisomes and does not require a reductant (AsA) to catalyze dismutation reactions [19]. Consequently, increased APX activity is an important factor in reducing the ascorbate availability for VDE and in decreasing the amplitude of NPQ. On the other hand, VDE activity can be artificially restricted by the well-known reductant agent dithiothreitol (DTT) [20] to study NPQ dynamics. The mechanism of DTT is likely to be related to its reducing action on disulfide bonds in the VDE molecule [20]. However, DTT does not interfere with the development 
of the trans-thylakoidal $\Delta \mathrm{pH}$ [8] regulating qE. Thus, feeding leaves DTT and AsA, which affect VDE activity in opposite ways, could be applied to distinct NPQ components for a better understanding of the influence of light quality on NPQ characteristics and amplitude.

Overall, our current understanding of NPQ activity suggests, that when operating in field conditions it determines canopy photosynthesis, biomass, and yield by preventing photoinhibition in response to rapidly changing environmental conditions [21]. However, under non-saturating light conditions in indoor farming systems (e.g., LED-based), more of the absorbed energy can be used for photochemistry when NPQ is not highly induced [22]. Thus, it would be favorable to restrict NPQ activity and to increase the speed of its recovery during relaxation [5], as its overly-protective persistence lowers the quantum yield of photosynthesis [21]. The effect of different light quality on NPQ amplitude has not been thoroughly investigated [5], even though NPQ activation is linked to the absorption of mostly blue (B) and red (R) light by photosynthetic pigments [22]. For this purpose, the RB spectrum supplemented with green $(G)$ light could be considered to ensure efficient photosynthesis, avoiding needless NPQ activation.

In the present study, we investigated the influence of the spectral quality of light on the dynamics of non-photochemical quenching, photosynthetic properties, and the absorbed energy partitioning in PSII in the presence of DTT and AsA in the leaves of tomato plants. For this purpose, we examined the kinetics of chlorophyll fluorescence induction and dark-relaxation and, in particular, proposed an original model of the fast induction and relaxation curves. We also analyzed the antioxidant activity of APX, SOD, and CAT enzymes, the photosynthetic pigment content, and the abundance of proteins related to the xanthophyll cycle (PsbS and VDE) or linear (cytochrome $b_{6} f$ subunit $f$; cyt $f$ ) and cyclic electron transport (PROTON GRADIENT REGULATION-LIKE1; PGRL1) building up the proton gradient across the thylakoid membrane. We hypothesized the following: (1) different types of monochromatic light have different impacts on the dynamics of non-photochemical quenching and that response is related to (2) different patterns of absorbed energy partitioning in PSII, (3) altered accumulation of photosynthetic pigments and NPQ-related proteins and (4) modified antioxidant capacity. The use of monochromatic R, G, and B light along with RGB (WL) lighting represents an opportunity to increase/decrease the proportions of desired wavebands in the mixed spectrum, thus increasing plant performance.

\section{Materials and Methods}

\subsection{Plant Material and Growth Conditions}

Tomato (Solanum lycopersicum L. cv. Malinowy Ozarowski) seeds, treated with antifungal powder (T75 DS/WS) were germinated in Petri dishes on sterile filter papers soaked in Milli-Q-water at $26^{\circ} \mathrm{C}$. For analysis, a tomato cultivar with reduced leaf dissection (potato leaf phenotype) [23] was chosen to maximize light absorption in the upper part of the canopy. The seedlings were transplanted to P9 containers $(9 \times 9 \times 10 \mathrm{~cm})$ and filled with the substrate (white and black peat, perlite and N:P:K = 9:5:10; $\mathrm{pH} 6.0-6.5$ ), divided into groups, and transferred to four growth chambers, with non-reflective black separators to eliminate light contamination. The plants were grown for 14 consecutive days under Px256 PxCrop LED lamps (PXM, Podleze, Poland) delivering $120 \mu \mathrm{mol} \mathrm{m}^{-2} \mathrm{~s}^{-1}$ of the RGB spectrum (R:G:B = 1:1:1; referred to as white light (WL)) or $80 \mu \mathrm{mol} \mathrm{m}^{-2} \mathrm{~s}^{-1}$ of monochromatic R, G or B light (RL, GL or BL, respectively). LED characteristics were as follows: red LEDs: peak wavelength $671 \mathrm{~nm}$, peak broadness at half peak height $25 \mathrm{~nm}$ (656-681 nm); green LEDs: 524, 40, 505-545 nm; and blue LEDs: 438, 20, 428-448 nm. WL treatment was used as the control group. Light composition and photosynthetic photon flux density (PPFD) were monitored daily by a calibrated spectroradiometer GL SPECTIS 5.0 Touch (GL Optic Lichtmesstechnik GmbH, Weilheim/Teck, Germany). The readings were averaged for six locations at the level of the apical bud and maintained by adjusting the distance between the light sources and the plant's canopy.

The containers with tomato plants cultivated under the same light treatment were turned twice a day. To avoid canopy shading and overlapping five plants per square meter 
of the illuminated area were cultivated. The photoperiod was $16 / 8 \mathrm{~h}$ (day/night; day 6:00 a.m.-10:00 p.m.), the average temperature was maintained at $25 / 22{ }^{\circ} \mathrm{C}$ (day/night) and relative air humidity was kept at $50-60 \%$. The plants were watered with tap water when necessary and fertilized once a week with $1 \%(w / v)$ tomato fertilizer (N:P:K = 9:9:27; Substral Scotts, Warszawa, Poland). The second leaf from above of plants 14-days-aftertransplanting (DAT) was used for subsequent analyses. All analyses were conducted between 8:00 a.m. and 12:00 p.m. Twenty tomato plants (two repetitions with ten plants per light treatment) were grown with each kind of light treatment.

\subsection{Pre-Illumination of Ascorbic Acid-and Dithiothreitol-Infiltrated Leaf Samples}

Leaf discs with a diameter of $10 \mathrm{~mm}$ were cut out (avoiding leaf veins) from the second leaf from above of plants 14-DAT in each group, transferred to Petri dishes, and incubated in a solution of $10 \mathrm{mM}$ ascorbic acid (AsA, VDE enzyme activator; Sigma-Aldrich, St. Louis, MO, USA) [1] or $5 \mathrm{mM}$ dithiothreitol (DTT, VDE enzyme inhibitor; Sigma-Aldrich) [24] or in distilled water (control, C) for $30 \mathrm{~min}$ in the dark. All solutions were buffered with $10 \mathrm{mM}$ piperazine-1,4-bis(2-ethanesulphonic acid) (PIPES; Sigma-Aldrich) [25]. To avoid light contamination discs were cut out directly under the lighting conditions of the chambers. After infiltration, leaf discs were pre-illuminated for $30 \mathrm{~min}$ with RGB light $(\mathrm{R}(627 \mathrm{~nm}): \mathrm{G}(530 \mathrm{~nm}): \mathrm{B}(447 \mathrm{~nm})=1: 1: 1)$ at a light intensity of approximately $500 \mu \mathrm{mol} \mathrm{m}^{-2} \mathrm{~s}^{-1} \pm 5 \mu \mathrm{mol} \mathrm{m}{ }^{-2} \mathrm{~s}^{-1}$ (LED Light Source SL-3500 lamp, Photon Systems Instruments, Drasov, Czech Republic). Light intensity applied for pre-illumination was chosen based on previous analyses $[26,27]$ to allow for the most pronounced acceleration of NPQ formation and to avoid any adverse effect on PSII activity at higher light intensities. Subsequently, leaves were re-darkened for $15 \mathrm{~min}$ to allow relaxation of the transthylakoid $\mathrm{pH}$ gradient without substantial reconversion of $\mathrm{Z}$ back to $\mathrm{V}$.

\subsection{Measurement of Chlorophyll Fluorescence (ChF) Induction Kinetics}

ChlF was measured at $25^{\circ} \mathrm{C}$ using a pulse amplitude-modulated (PAM) fluorometer (Maxi IMAGING PAM M-Series, Walz, Effeltrich, Germany) on the adaxial side of the leaf discs. Leaf discs were positioned on wet filter paper in a self-built cuvette and continuously supplied with moistened air throughout the experiment. To avoid spatial and temporal heterogeneity of chemical infiltration, four circle-shaped areas of interest (AOIs) were selected and averaged for each replicate. The minimal (dark) fluorescence level (Fo) was measured using measuring modulated blue light $(450 \mathrm{~nm})$, which was sufficiently low $\left(0.01 \mu \mathrm{mol} \mathrm{m} \mathrm{m}^{-2} \mathrm{~s}^{-1}\right)$ that it would not induce any significant variable fluorescence. The maximal fluorescence level $(\mathrm{Fm})$ with all PSII reaction centers closed was determined by a $0.8 \mathrm{~s}$ saturating blue light pulse $(\mathrm{SP}=450 \mathrm{~nm})$ at $5000 \mu \mathrm{mol} \mathrm{m}{ }^{-2} \mathrm{~s}^{-1}$ in dark-adapted samples. The maximum PSII photochemical efficiency $(\mathrm{Fv} / \mathrm{Fm})$ was derived from that $(\mathrm{Fv} / \mathrm{Fm}=(\mathrm{Fm}-\mathrm{Fo}) / \mathrm{Fm})$. Then, for quenching analysis, leaf samples were illuminated for $20 \mathrm{~min}$ at $185 \mu \mathrm{mol} \mathrm{m}{ }^{-2} \mathrm{~s}^{-1}$ of blue actinic light $(\mathrm{AL}=450 \mathrm{~nm}$ ) (induction), followed by $20 \mathrm{~min}$ of dark incubation (relaxation). AL intensity during the measurement was chosen to be just sufficient to provide stable NPQ amplitude over the induction phase [26]. To determine the NPQ induction, SPs (5000 $\mu \mathrm{mol} \mathrm{m}^{-2} \mathrm{~s}^{-1}$, duration $\left.0.8 \mathrm{~s}\right)$ were applied every $10 \mathrm{~s}$ apart during the first $50 \mathrm{~s}$ of AL illumination (fast induction), followed by five flashes given every $240 \mathrm{~s}$ (slow induction). Subsequently, the AL was turned off and the dark relaxation of NPQ was determined by SPs spaced $10 \mathrm{~s}$ during the first $50 \mathrm{~s}$ of dark incubation (fast relaxation) followed by five flashes given every $240 \mathrm{~s}$ (middle and slow relaxation). The saturating light flashes were time-separated to minimize their contribution to NPQ formation and relaxation.

Fluorescence yields obtained during the analysis were combined to calculate the Stern-Volmer NPQ $=\left(\mathrm{Fm}-\mathrm{Fm}^{\prime}\right) / \mathrm{Fm}^{\prime}$ (where $\mathrm{Fm}^{\prime}$ is the maximal level of chlorophyll fluorescence in light) and the complementary effective quantum yield of PSII photochemistry $\Phi P S I I=\left(\mathrm{Fm}^{\prime}-\mathrm{F}\right) / \mathrm{Fm}^{\prime}$ (where $\mathrm{F}$ is fluorescence yield in conjunction with an applied saturation pulse) [28], the non-regulated energy dissipation $\Phi \mathrm{NO}=1 /(\mathrm{NPQ}+1$ 
$+\mathrm{qL}(\mathrm{Fm} / \mathrm{Fo}-1)$ ) (where $\mathrm{qL}$ is the coefficient of photochemical quenching based on the lake model of PSII antenna pigment organization) and regulated energy dissipation $\Phi N P Q=1-\Phi P S I I-\Phi N O[8,29]$. The assessed NPQ value exceeded unity; thus, its value is presented as NPQ/4 for better correspondence with $\Phi$ NPQ. Each measurement comprised six replicates.

\subsection{Antioxidant Enzyme Activity Assay and MDA Measurements}

Fresh leaf samples, collected before pre-illumination, were immediately frozen in liquid nitrogen and ground to a fine powder using a chilled mortar and pestle. Soluble proteins were extracted by homogenizing $100 \mathrm{mg}$ of leaf powder in $1 \mathrm{~mL}$ of ice-cold $50 \mathrm{mM}$ phosphate buffer ( $\mathrm{pH} 7.8$ for SOD and 7.0 for APX/CAT assay) containing $1 \mathrm{mM}$ EDTA ( $\mathrm{pH} 8.0)$ and $5 \%(w / v)$ polyvinylpolypyrrolidone (PVPP) and $1 \mathrm{mM}$ ascorbate (for APX assay). Insoluble material was removed by centrifugation at $10,000 \times \mathrm{g}$ for $30 \mathrm{~min}$ at $4{ }^{\circ} \mathrm{C}$. The collected supernatant, referred to as the "extract", was used to determine antioxidant enzyme activity.

For ascorbate peroxidase (APX; EC 1.11.1.11) determination, previously described assays $[30,31]$ were performed. The reaction mixture, containing $50 \mathrm{mM}$ phosphate buffer (pH 7.0), $1 \mathrm{mM}$ sodium ascorbate, and $50 \mu \mathrm{L}$ of the extract, was first equilibrated for $3 \mathrm{~min}$. The reaction was started by the addition of $0.5 \mathrm{mM} \mathrm{H}_{2} \mathrm{O}_{2}$ and monitored by the decrease in absorbance at $290 \mathrm{~nm}$ due to ascorbate oxidation every $30 \mathrm{~s}$ for $3 \mathrm{~min}$ at $25{ }^{\circ} \mathrm{C}$ (extinction coefficient of $2.8 \mathrm{mM}^{-1} \mathrm{~cm}^{-1}$ ). The assay was performed in four replicates for each treatment.

The activity of superoxide dismutase (SOD; EC 1.15.1.1) was determined using the previous assay [32]. For the assay, $40 \mu \mathrm{L}$ of each extract was mixed with $100 \mu \mathrm{L}$ of $0.75 \mathrm{mM}$ nitroblue tetrazolium (NBT), $2 \mu \mathrm{L}$ of $0.5 \mathrm{M}$ EDTA ( $\mathrm{pH} 8.0$ ), and $20 \mu \mathrm{L}$ of $0.1 \mathrm{mM}$ riboflavin. Due to the photosensitivity of the solution, the procedure was carried out under low light. Samples containing the reaction solution were irradiated under a set of fluorescent light tubes of $40 \mu \mathrm{mol} \mathrm{m}{ }^{-2} \mathrm{~s}^{-1}$ for $10 \mathrm{~min}$ to start the reaction. The absorbance of the irradiated and non-irradiated samples was determined at $560 \mathrm{~nm}$. One unit of enzyme activity (U) was taken as the amount of enzyme that reduced the absorbance reading to $50 \%$ compared with tubes that lacked the enzyme [33]. The assay was performed in four replicates for each treatment.

The activity of catalase (CAT; EC 1.11.1.6) was determined as described elsewhere [34]. In brief, $20 \mu \mathrm{L}$ enzyme extract was added to $405 \mu \mathrm{L} 50 \mathrm{mM}$ potassium phosphate buffer (pH 7.0) and $250 \mu \mathrm{L}$ water. After $5 \mathrm{~min}$ of pre-incubation at $26^{\circ} \mathrm{C}, 750 \mu \mathrm{L}$ of $10 \mathrm{mM}$ $\mathrm{H}_{2} \mathrm{O}_{2}$ was added to start the reaction. The decomposition of $\mathrm{H}_{2} \mathrm{O}_{2}$ was followed directly by decreased absorbance at $240 \mathrm{~nm}$. Enzyme activity was computed by calculating the decomposed amount of $\mathrm{H}_{2} \mathrm{O}_{2}$, every $20 \mathrm{~s}$ for $3 \mathrm{~min}$ at $26{ }^{\circ} \mathrm{C}$. The calculations used an absorbance coefficient of $43.6 \mathrm{M}^{-1} \mathrm{~cm}^{-1}$ at $240 \mathrm{~nm}$ [35]. The assay was performed in four replicates for each treatment.

The level of oxidative damage to membranes was estimated indirectly by assessing the by-products of lipid peroxidation reacted with thiobarbituric acid (TBA), including malondialdehyde (MDA) content. The assay was in accordance with a previous procedure [32]. First, $100 \mathrm{mg}$ of liquid nitrogen-ground leaf powder was homogenized in $1 \mathrm{~mL}$ of $10 \%(w / v)$ TCA and centrifuged at $10,000 \times g$ for $15 \mathrm{~min}$. Then, $1 \mathrm{~mL}$ of supernatant was mixed with $1 \mathrm{~mL}$ of $0.6 \%(w / v)$ TBA, heated at $95^{\circ} \mathrm{C}$ for $30 \mathrm{~min}$, and then quickly cooled down on ice to room temperature. After centrifugation at $10,000 \times g$ for $10 \mathrm{~min}$, the absorbance (A) of the 10-fold diluted supernatants was measured at $532 \mathrm{~nm}$ and values corresponding to non-specific absorption at $450 \mathrm{~nm}$ and a correction factor for non-specific turbidity at $600 \mathrm{~nm}$. MDA concentration determined on a fresh weight basis was calculated as described elsewhere [36] with the following Formula (1):

$$
\operatorname{MDA}\left(\mu \mathrm{mol} \mathrm{g}^{-1} \mathrm{FW}\right)=6.45 \times\left(\mathrm{A}_{532}-\mathrm{A}_{600}\right)-0.56 \times \mathrm{A}_{450}
$$

The assay was performed in four replicates for each treatment. 


\subsection{Pigment Determination}

The concentrations of chlorophyll $a$ and $b(\mathrm{Chl} a, b)$ and total carotenoids were measured spectrophotometrically with a Spectronic Helios Gamma UV-Vis spectrophotometer (Thermo Fisher, Waltham, MA, USA) after being dissolved in dimethyl sulfoxide (DMSO). Pigments were extracted from leaf discs (3 $\mathrm{mm}$ in diameter, approximately $20 \mathrm{mg}$ of tissue) in $1.5 \mathrm{~mL}$ DMSO. Samples, kept in dim light, were vortexed for $1 \mathrm{~min}$, then capped and incubated for $3 \mathrm{~h}$ at $65^{\circ} \mathrm{C}$ with inversion every $10 \mathrm{~min}$ to improve extraction. Then the sample mixture was centrifuged at $10,000 \times g$ for $15 \mathrm{~min}$, and the supernatant was carefully collected without disturbing the plant tissue, transferred to a new tube, and mixed again for $15 \mathrm{~s}$. An aliquot $(1 \mathrm{~mL})$ of the uppermost supernatant layer was used for pigment determination at 480, 649, and $665 \mathrm{~nm}$, according to an optimized method described elsewhere [37]. The assay was performed in ten replicates for each treatment.

\subsection{Western Blot Analysis}

Leaf-soluble proteins were extracted with a Plant Total Protein Extraction Kit (SigmaAldrich) according to the manufacturer's instructions. In brief, $200 \mathrm{mg}$ of the liquid nitrogen-ground leaf powder, protected from proteolysis by a protease inhibitor cocktail, was washed with a methanol working solution and acetone. A purified tissue pellet was used for total protein extraction with a chaotropic protein reagent. The protein content was estimated using Coomassie reagent (Thermo Fisher Scientific) and bovine serum albumin as a standard [38].

Then, optimized amounts of extracted proteins were loaded onto precast $4-20 \%$ gradient TGX polyacrylamide gels (Bio-Rad, Hercules, CA, USA) and run with a constant voltage of $200 \mathrm{~V}$ for $20 \mathrm{~min}$. Separated proteins were transferred to nitrocellulose membranes $(0.45$ or $0.2 \mu \mathrm{m}$ pore size; Bio-Rad) by semi-dry electroblotting $\left(1.5 \mathrm{~mA}\right.$ per $\left.\mathrm{cm}^{2}, 20 \mathrm{~min}\right)$. Airdried blots were blocked with $5 \%$ non-fat dry milk blocking reagent $\left(1 \mathrm{~h}, 25^{\circ} \mathrm{C}\right)$ (Bio-Rad) and incubated with primary antibodies against PsbS (AS09 533; 1:1000), VDE (AS15 3091; 1:1000), PGRL1 (AS10 725/AS19 4311; 1:1000), cytf (AS08 306; 1:5000) and ATPB (beta subunit of ATP synthase; AS05 085; 1:5000; loading control) (Agrisera, Vännäs, Sweden) overnight at $4{ }^{\circ} \mathrm{C}$. Next membranes were washed in Tween-TBS buffer (TTBS; $0.05 \%$ Tween 20, $20 \mathrm{mM}$ Tris, $500 \mathrm{mM} \mathrm{NaCl}$ ) and incubated with horseradish peroxidase-conjugated secondary antibody (AS09 602; 1:5000-1:10,000) for $1 \mathrm{~h}$ at $25^{\circ} \mathrm{C}$ with agitation. The blots were washed again in TTBS and developed for 5-10 min with a colorimetric detection reagent using a Pierce ${ }^{\mathrm{TM}}$ DAB Substrate Kit (3,3'-diaminobenzidine tetrahydrochloride; Thermo Fisher Scientific). Quantification of the protein bands of the Western Blot (WB) membranes visualized with DAB was done using densitometric analysis (ImageJ v.1.49, National Institutes of Health, Bethesda, MD, USA) [39]. The samples were analyzed three times. The relative amount of proteins was calculated using the maximum value of protein noticed in WL plants.

\subsection{Model for Fitting of Experimental Data of Fast $q E N P Q$}

Curve fitting of NPQ induction and relaxation was performed using Origin version 2021b (OriginLab Corporation, Northampton, MA, USA). The model for fitting experimental data of fast (50 s) qE NPQ induction/relaxation in AsA-, DTT- or water-treated samples, was applied as specified for each case and reported with the adjusted $R^{2}\left(R_{a}{ }^{2}\right)$ value to determine the goodness of data fitting (Tables 1 and 2). We applied the following:

- Logistic regression equation for fitting data $(x)$ of fast $\mathrm{qE}$ NPQ induction:

$$
y=\frac{A_{1}-A_{2}}{1+\left(\frac{x}{x_{0}}\right)^{\alpha}}+A_{2}
$$

where $A_{1}$ is the minimum asymptote, $A_{2}$ is the maximum asymptote, $x_{0}$ is the value of the inflection point and $\alpha$ is the slope of the logistic growth rate (steepness of the curve).

- Polynomial cubic regression equation for fitting data $(x)$ of fast $\mathrm{qE}$ NPQ relaxation: 


$$
y=A+B x+C x^{2}+D x^{3}
$$

where $A$ is the offset and $B, C$ and $D$ are coefficients.

\subsection{Statistical Analysis}

Statistical analysis was performed using Statistica 13.3 software (StatSoft Inc., Oklahoma, OK, USA). The normal distribution of variables was verified using the Shapiro-Wilk test and the equality of variances was evaluated using Levene's test. One-way ANOVA and post-hoc Tukey's HSD tests were employed to analyze the differences between the investigated groups. The data are presented as mean with standard deviation $( \pm \mathrm{SD})$. Statistical significance was determined at the 0.05 level $(p=0.05)$.

\section{Results}

\subsection{NPQ Formation in the Presence of AsA and DTT}

The induction of NPQ during 20 min of illumination at a light intensity of $185 \mu \mathrm{mol} \mathrm{m}^{-2} \mathrm{~s}^{-1}$ was measured in tomato plants grown under different types of light quality: monochromatic R (RL), G (GL), or B (BL) light at $80 \mu \mathrm{mol} \mathrm{m}^{-2} \mathrm{~s}^{-1}$, or combined RGB spectrum (WL) at $120 \mu \mathrm{mol} \mathrm{m}{ }^{-2} \mathrm{~s}^{-1}$. To overcome possible limitations of NPQ formation by the rate of $Z$ synthesis, especially in plants grown under monochromatic light, NPQ dynamics were investigated after pre-illumination of leaf samples for 30 min with RGB light at $500 \mu \mathrm{mol} \mathrm{m} \mathrm{m}^{-2} \mathrm{~s}^{-1}$. Before the onset of pre-illumination, leaves were infiltrated with $10 \mathrm{mM}$ AsA or $5 \mathrm{mM}$ DTT, or incubated in distilled water (control, C). DTT is an inhibitor of VDE that promotes NPQ induction, whereas AsA is a cofactor for the VDE enzyme. This approach allows us to examine the ability of plants grown under different light quality in terms of the subsequent $Z$ formation during pre-illumination and evaluate the contribution of the NPQ components to the overall non-photochemical activity within re-darkened samples.

In water-incubated samples, a stable maximum NPQ value was reached after about $10 \mathrm{~min}(600 \mathrm{~s})$ of AL illumination (Figure 1). However, analyzed NPQ kinetics revealed significant differences in maximal amplitude between groups. The highest NPQ level was observed in BL and RL plants, reaching 1.0 and about 0.84, respectively, whereas, in WL and GL plants, the maximum level stabilized at 0.55 and 0.34 , respectively, after $600 \mathrm{~s}$. Moreover, an analysis of the kinetics of NPQ induction revealed the existence of two main phases, rapid (development time about $50 \mathrm{~s}$ ) and slower (development time about $600 \mathrm{~s}$ ). 

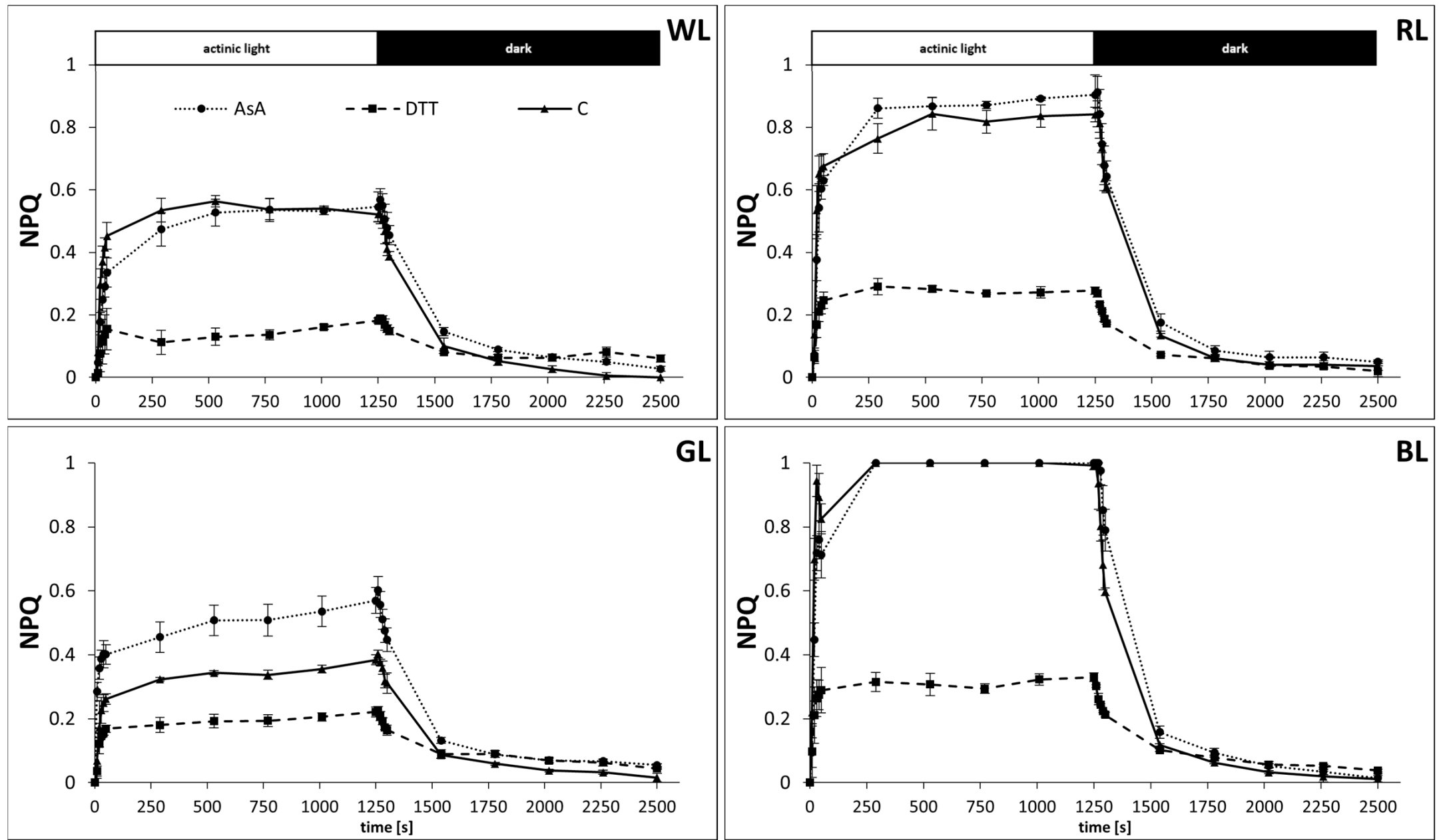

Figure 1. Dynamic changes of non-photochemical quenching, NPQ, in leaves of tomato plants (Solanum lycopersicum L. cv. Malinowy Ozarowski) grown under different LED light conditions (see Material and Methods for details). $10 \mathrm{~mm}$ diameter leaf discs were infiltrated with $10 \mathrm{mM}$ ascorbic acid (AsA) or $5 \mathrm{mM}$ dithiothreitol (DTT), or distilled water (C, control) for $30 \mathrm{~min}$ in the dark, followed by pre-illumination at $500 \mu \mathrm{mol} \mathrm{m} \mathrm{s}^{-1}$ of RGB light for next $30 \mathrm{~min}$. The dynamics of the NPQ were determined in re-darkened leaf samples illuminated for $20 \mathrm{~min}$ at $185 \mu \mathrm{mol} \mathrm{m}{ }^{-2} \mathrm{~s}^{-1}$ of blue actinic light $(\mathrm{AL}=450 \mathrm{~nm}$ ) (induction), followed by $20 \mathrm{~min}$ of dark incubation (relaxation), and derived from the maximum fluorescence induced by saturation pulses (5000 $\mu \mathrm{mol} \mathrm{m} \mathrm{m}^{-2} \mathrm{~s}^{-1}, 0.8 \mathrm{~s}$ ) at each of the measuring points. Each data point represents the average $\pm \mathrm{SD}$ of six independent measurements $(n=6)$. 
The results of the rapid phase of NPQ induction, assigned to qE, are described below. In the case of the slower phase assigned to qZ, its amplitude contributed to about $20 \%$ of the total NPQ value $(19,20,24$, and $16 \%$ in WL, RL, GL, and BL samples, respectively). DTT infiltration, however, significantly reduced the NPQ amplitude. The fraction of lost NPQ might be attributed to the $Z$ synthesized with VDE, as the amplitude of quenching in DTT-treated samples did not differ significantly between 50 and $600 \mathrm{~s}$ of AL illumination. In contrast, AsA infiltration significantly increased the maximal NPQ amplitude, but only in the GL leaves (Figure 1).

Similarly, the relaxation of NPQ presented distinct phases: rapid, which contributed to the first $50 \mathrm{~s}$ of relaxation (1250-1300 s), middle (4 min, 1300-1540 s), and slow (last $16 \mathrm{~min}$, 1540-2500 s) (Figure 1). The results of rapid and middle NPQ relaxation, related mostly to $\mathrm{pH}$ collapse, are described below. In the case of the slow phase of NPQ relaxation, it was found to collapse almost completely after 20 min of dark incubation, indicating that the reaction of $\mathrm{Z}$ epoxidation back to $\mathrm{V}$ was not interrupted by the applied chemicals.

\subsection{Kinetics of Rapid Phase of NPQ Induction}

The dominant rapid phase ( $\mathrm{qE}$ ) of water-incubated samples reached values of 0.45 , $0.67,0.26$, and 0.82 for $\mathrm{WL}, \mathrm{RL}, \mathrm{GL}$, and BL, respectively, after about $50 \mathrm{~s}$ of AL illumination. At the same time, DTT infiltration was unable to completely suppress the NPQ rise, however, the leaf samples presented a significantly reduced $\mathrm{qE}$ amplitude, reaching 0.15 , $0.25,0.17$, and 0.29 for WL, RL, GL, and BL, respectively (Figure 2). In general, the initial slope of the NPQ fast phase formation in water-treated samples was much steeper in the BL and RL leaves $\left(\alpha_{\mathrm{BL}}=\alpha_{\mathrm{RL}}=3.89\right)$ than that in WL leaves $\left(\alpha_{\mathrm{WL}}=2.79\right)($ Table 1 , Figure 2$)$, reaching a near-maximal value after $30 \mathrm{~s}$ of AL illumination.

Table 1. The parameters of the logistic regression model employed to fit the experimental data $(x)$ of fast (50 s) qE NPQ induction in the AsA-, DTT- or water-treated samples (C). The fit equation: $y=\frac{A_{1}-A_{2}}{1+\left(\frac{x}{x_{0}}\right)^{\alpha}}+A_{2}$, where $A_{1}$-minimum asymptote, $A_{2}$-maximum asymptote, $x_{0}$-the value of the inflection point, $\alpha$-a slope of the logistic growth rate (steepness of the curve), $\mathrm{R}_{\mathrm{a}}{ }^{2}$-the adjusted r-square value, determining the goodness of fit, accounts for the degrees of freedom. WL-the R:G:B = 1:1:1 at $120 \mu \mathrm{mol} \mathrm{m}^{-2} \mathrm{~s}^{-1}$; RL, GL or BL-monochromatic red (R), green (G) or blue (B) light (L) at $80 \mu \mathrm{mol} \mathrm{m} \mathrm{m}^{-2} \mathrm{~s}^{-1}$, respectively.

\begin{tabular}{ccccccc}
\hline Light Quality & Treatment & $\boldsymbol{A}_{\mathbf{1}}$ & $\boldsymbol{A}_{\mathbf{2}}$ & $\boldsymbol{x}_{\mathbf{0}}$ & $\boldsymbol{\alpha}$ & $\mathbf{R}_{\mathbf{a}}{ }^{\mathbf{2}}$ \\
\hline \multirow{3}{*}{ WL } & AsA & -0.00252 & 0.38013 & 22.09031 & 2.22938 & 0.99203 \\
& DTT & -0.00167 & 0.17035 & 22.17636 & 2.58926 & 0.99382 \\
& C & -0.00274 & 0.46039 & 16.73017 & 2.78761 & 0.99076 \\
\hline \multirow{2}{*}{ RL } & AsA & -0.00147 & 0.64659 & 18.21531 & 3.37634 & 0.99971 \\
& DTT & $-3.29693 \times 10^{-4}$ & 0.25832 & 15.6885 & 2.34694 & 0.99808 \\
& C & $3.59786 \times 10^{-4}$ & 0.68169 & 14.29079 & 3.89071 & 0.99978 \\
\hline \multirow{2}{*}{ GL } & AsA & $1.23493 \times 10^{-5}$ & 0.42252 & 6.1032 & 1.47486 & 0.99937 \\
& DTT & $-4.9053 \times 10^{-4}$ & 0.16698 & 14.89135 & 3.05313 & 0.99232 \\
& C & $6.50152 \times 10^{-6}$ & 0.2812 & 16.37096 & 2.30662 & 0.99995 \\
\hline \multirow{3}{*}{ BL } & AsA & 0.02089 & 0.75903 & 18.24241 & 4.49567 & 0.9808 \\
& DTT & $9.39587 \times 10^{-5}$ & 0.30166 & 13.81813 & 2.34655 & 0.99839 \\
& C & 0.00485 & 0.8969 & 13.65348 & 3.89107 & 0.95673 \\
\hline
\end{tabular}




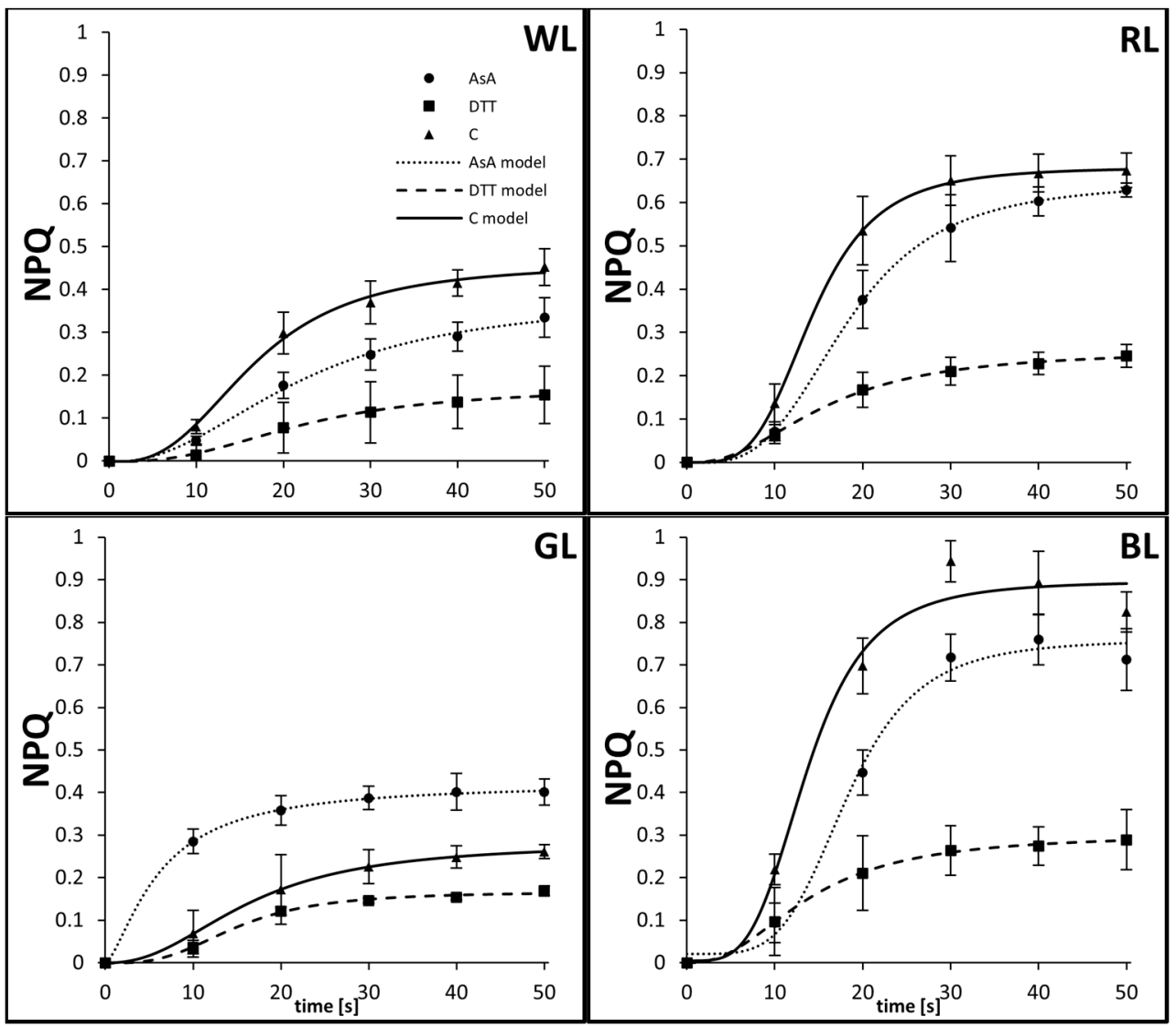

Figure 2. Dynamic changes of fast induction of non-photochemical quenching, NPQ, in leaves of tomato plants (Solanum lycopersicum L. cv. Malinowy Ozarowski) grown under different LED light conditions (see Material and Methods for details). $10 \mathrm{~mm}$ diameter leaf discs were infiltrated with $10 \mathrm{mM}$ ascorbic acid (AsA) or $5 \mathrm{mM}$ dithiothreitol (DTT), or distilled water (C, control) for $30 \mathrm{~min}$ in the dark, followed by pre-illumination at $500 \mu \mathrm{mol} \mathrm{m} \mathrm{m}^{-2} \mathrm{~s}^{-1}$ of RGB light for next $30 \mathrm{~min}$. The dynamics of the NPQ induction were determined in re-darkened leaf samples and derived from saturation pulses $\left(5000 \mu \mathrm{mol} \mathrm{m} \mathrm{m}^{-2} \mathrm{~s}^{-1}, 0.8 \mathrm{~s}\right)$ applied every $10 \mathrm{~s}$ during the first $50 \mathrm{~s}$ of blue actinic light $(\mathrm{AL}=450 \mathrm{~nm})$ illumination. Each data point represents the average $\pm \mathrm{SD}$ of six independent measurements $(n=6)$. The logistic regression model was employed to fit the experimental data of fast (50 s) qE NPQ induction in the AsA-, DTT- or water-treated samples. Fitting was applied as specified in Material and Methods and reported with an adjusted $\mathrm{R}^{2}\left(\mathrm{R}_{\mathrm{a}}{ }^{2}\right)$ value (Table 1$)$ to determine the goodness of data fitting.

On the contrary, in the GL samples, the $\mathrm{qE}$ rise was distinctly slowed down $\left(\alpha_{\mathrm{GL}}=2.31\right)$. Despite the higher PPFD as well as the red and blue light included in the spectrum, the WL samples also presented a slower qE rise than RL or BL. Moreover, in the BL and RL samples, DTT feeding reduced not only the $\mathrm{qE}$ amplitude but also the steepness of the curve (to $\alpha=2.35$ in both light conditions). In contrast, DTT-fed WL leaves presented only slightly decreased $\alpha$, while GL showed an increased dynamic of qE rise, despite its lower maximal amplitude (Table 1). On the other hand, the AsA infiltration, which was expected to induce $\mathrm{Z}$ formation during the pre-illumination phase and thus to accelerate $\mathrm{qE} \mathrm{NPQ}$ formation, visibly increased the qE amplitude only in GL samples, whereas the WL- and BL-grown leaves presented diminished qE values after the first $50 \mathrm{~s}$. However, in AsA-fed GL samples, qE quickly reached a plateau (the inflection point, $x_{0}$, occurred after the first $6 \mathrm{~s}$ of induction), compared to WL (Table 1). 


\subsection{Kinetics of Rapid and Middle Phases of NPQ Relaxation}

An analysis of the kinetics of the fast NPQ relaxation demonstrated that it was rather slow, especially in the GL group (Table 2, Figure 3), when compared to the fast induction of NPQ. During the first $50 \mathrm{~s}$, the amplitude of NPQ relaxed about 25, 27, 18, and 39\% in control conditions for WL, RL, GL, and BL samples, respectively. After the next 4 min of dark incubation, the NPQ amplitude further decreased by about $72,79,71$, and $82 \%$ for WL, RL, GL, and BL samples, respectively. DTT-infiltrated samples presented similar amplitudes of NPQ relaxation during the fast phase $(17,39,27$, and $36 \%$ for $\mathrm{WL}, \mathrm{RL}, \mathrm{GL}$, and BL samples, respectively), whereas the rate of the middle phase of relaxation was significantly restricted $(33,28,43$ and $42 \%$ for $\mathrm{WL}, \mathrm{RL}, \mathrm{GL}$ and BL samples, respectively). In the case of AsA-infiltrated leaves, the relaxation dynamics of rapid and middle phase were similar to those noted for control (water) samples, except for BL, which presented a significantly reduced amplitude ( $21 \%$ compared to $39 \%$ ) of the fast NPQ relaxation. Thus, we speculate that AsA stimulates the formation of $Z$ during AL illumination; therefore, the relaxation of NPQ activated by the collapse of $\Delta \mathrm{pH}$ is prolonged due to higher $\mathrm{Z}$ accumulation. Overall, the results document that the rapid and middle phases of NPQ relaxation can be predominantly assigned to the $\mathrm{qE}$ component and represent $\mathrm{pH}$-regulated and PsbS-dependent processes [27]. Thus, the slower rate of NPQ relaxation within DTTfed leaves might be attributed to restricted proton consumption as measured within Fv/Fm (Figure 4) and ФPSII (Figure 5). However, the rate of middle phase relaxation also seems to be related to the pool of $\mathrm{Z}$ as documented for AsA-infiltrated BL leaves.

Table 2. The parameters of the polynomial cubic regression model employed to fit the experimental data $(x)$ of fast (50 s) qE NPQ relaxation in the AsA-, DTT- or water-treated samples (C). The fit equation: $y=A+B x+C x^{2}+D x^{3}$, where $A$-offset, $B, C$ and $D$-coefficients, $\mathrm{R}_{\mathrm{a}}{ }^{2}$ - the adjusted r-square value, determining the goodness of fit, accounts for the degrees of freedom. WL-the R:G:B = 1:1:1 at $120 \mu \mathrm{mol} \mathrm{m} \mathrm{m}^{-2} \mathrm{~s}^{-1}$; RL, GL or BL-monochromatic red (R), green (G) or blue (B) light (L) at $80 \mu \mathrm{mol} \mathrm{m} \mathrm{m}^{-2} \mathrm{~s}^{-1}$, respectively.

\begin{tabular}{ccccccc}
\hline Light Quality & Treatment & $\boldsymbol{A}$ & $\boldsymbol{B}$ & $\boldsymbol{C}$ & $\boldsymbol{D}$ & $\mathbf{R}_{\mathbf{a}}{ }^{2}$ \\
\hline \multirow{3}{*}{ WL } & AsA & -6808.2723 & 15.96759 & -0.01248 & $3.25 \times 10^{-6}$ & 0.98669 \\
& DTT & -2209.638 & 5.17863 & -0.00404 & $1.05247 \times 10^{-6}$ & 0.99798 \\
& C & -4908.0904 & 11.49698 & -0.00897 & $2.33333 \times 10^{-6}$ & 0.97961 \\
\hline \multirow{2}{*}{ RL } & AsA & -13877.6622 & 32.62703 & -0.02556 & $6.67284 \times 10^{-6}$ & 0.99688 \\
& DTT & -2583.3524 & 6.08759 & -0.00478 & $1.25 \times 10^{-6}$ & 0.98621 \\
& C & -11791.3213 & 27.66722 & -0.02163 & $5.63579 \times 10^{-6}$ & 0.98203 \\
\hline \multirow{2}{*}{ GL } & AsA & -8712.6496 & 20.45127 & -0.016 & $4.16975 \times 10^{-6}$ & 0.96758 \\
& DTT & -2915.1715 & 6.84801 & -0.00536 & $1.39815 \times 10^{-6}$ & 0.99193 \\
& C & -5768.1806 & 13.53744 & -0.01059 & $2.75926 \times 10^{-6}$ & 0.95141 \\
\hline & AsA & -1902.5802 & 4.30528 & -0.00324 & $8.0864 \times 10^{-7}$ & 0.90916 \\
& DTT & -620.6656 & 1.50338 & -0.00121 & $3.24074 \times 10^{-7}$ & 0.98593 \\
& C & -14325.4182 & 33.57812 & -0.02622 & $6.82407 \times 10^{-6}$ & 0.99645 \\
\hline
\end{tabular}

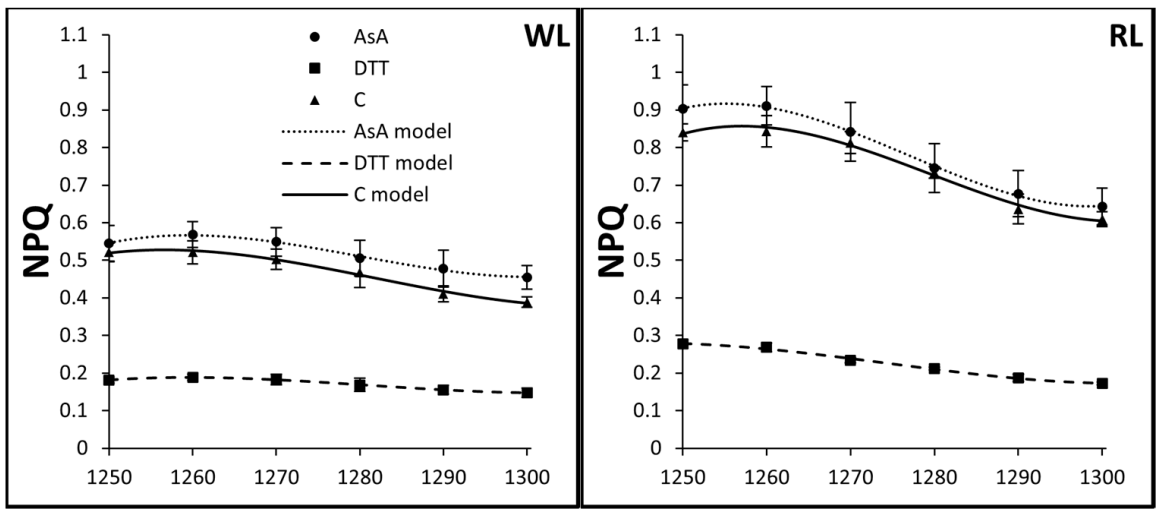

Figure 3. Cont. 


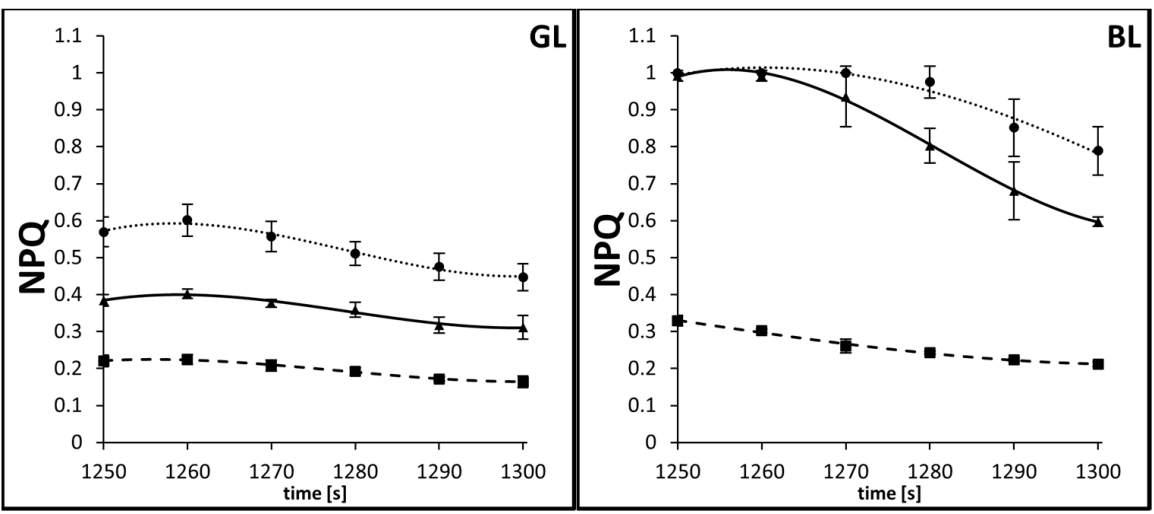

Figure 3. Dynamic changes of fast relaxation of non-photochemical quenching, NPQ, in leaves of tomato plants (Solanum lycopersicum L. cv. Malinowy Ozarowski) grown under different LED light conditions (see Material and Methods for details). $10 \mathrm{~mm}$ diameter leaf discs were infiltrated with $10 \mathrm{mM}$ ascorbic acid (AsA) or $5 \mathrm{mM}$ dithiothreitol (DTT), or distilled water (C, control) for $30 \mathrm{~min}$ in the dark, followed by pre-illumination at $500 \mu \mathrm{mol} \mathrm{m} \mathrm{m}^{-2} \mathrm{~s}^{-1}$ of RGB light for next $30 \mathrm{~min}$. The dynamics of the NPQ relaxation were determined in leaf samples immediately after actinic light turn off and derived from saturation pulses $\left(5000 \mu \mathrm{mol} \mathrm{m} \mathrm{m}^{-2} \mathrm{~s}^{-1}, 0.8 \mathrm{~s}\right)$ applied every $10 \mathrm{~s}$ during the first $50 \mathrm{~s}$ of darkness. Each data point represents the average \pm SD of six independent measurements $(n=6)$. The cubic polynomial regression model was employed to fit the experimental data of fast (50 s) qE NPQ relaxation in the AsA-, DTT- or water-treated samples. Fitting was applied as specified in Material and Methods and reported with an adjusted $\mathrm{R}^{2}\left(\mathrm{R}_{\mathrm{a}}{ }^{2}\right)$ value (Table 2$)$ to determine the goodness of data fitting.

\subsection{Maximum Quantum Yield and Photosynthetic Energy Partitioning in PSII}

For unstressed leaves, the value of Fv/Fm photosynthesis is highly consistent, with a value of about 0.83 , and correlates to the maximum quantum yield of photosynthesis, while the existence of any type of "stress" lowers Fv/Fm [40]. An analysis of Fv/Fm demonstrates that light quality influenced the activity of PSII (Figure 4). The highest Fv/Fm value of water-incubated samples was observed in plants grown under monochromatic blue $(\mathrm{Fv} / \mathrm{Fm}=0.751)$ and the lowest under green $(\mathrm{Fv} / \mathrm{Fm}=0.629)$ and $\mathrm{red}(\mathrm{Fv} / \mathrm{Fm}=0.634)$ light. At the same time, white light-grown leaves presented a higher $\mathrm{Fv} / \mathrm{Fm}$ value (0.711) than GL or RL, revealing the positive influence on PSII vitality of including B light in the spectrum. DTT infiltration did not cause serious PSII damage, with decreased Fv/Fm by about 4, 5, and 3\% for WL, GL, and BL, respectively. On the contrary, AsA-infiltrated leaves presented increased Fv/Fm in GL and BL by about 13 and 5\%, respectively. It should be noted, however, that the observed Fv/Fm values, in all treatments, were lower than expected indicating stressful conditions. A likely explanation is that leaf samples of plants grown under low light conditions were subsequently exposed to relatively high-intensity light to accelerate NPQ formation. 


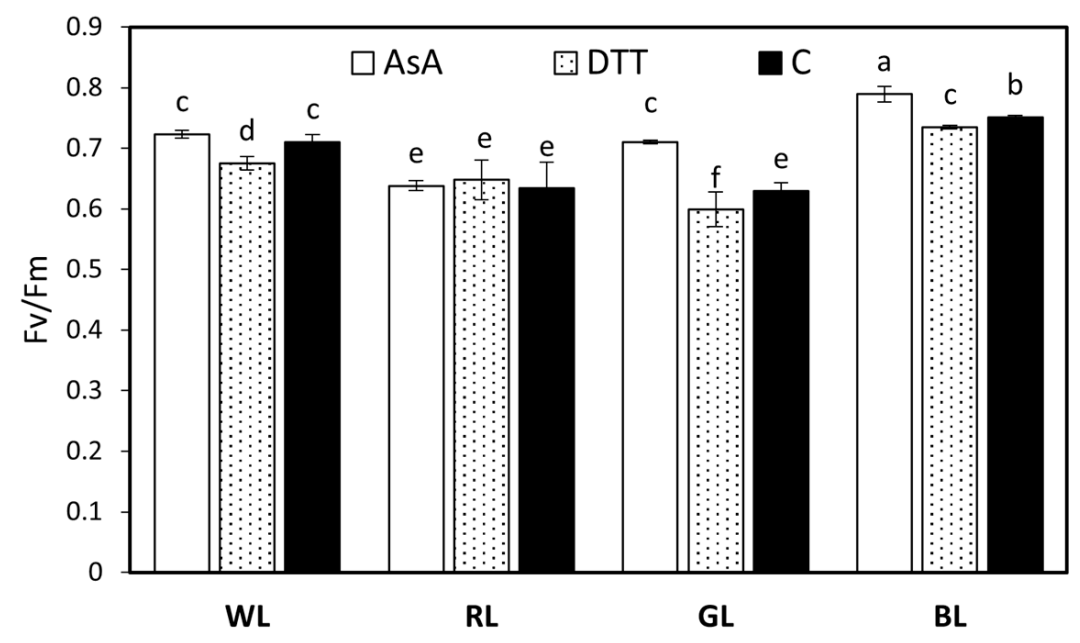

Figure 4. The maximal photochemical yield of PSII, Fv/Fm, in leaves of tomato plants (Solanum lycopersicum L. cv. Malinowy Ozarowski) grown under different light conditions (see Material and Methods for details). $10 \mathrm{~mm}$ diameter leaf discs were infiltrated with $10 \mathrm{mM}$ ascorbic acid (AsA) or $5 \mathrm{mM}$ dithiothreitol (DTT), or distilled water (C, control) for $30 \mathrm{~min}$ in the dark, followed by pre-illumination at $500 \mu \mathrm{mol} \mathrm{m}{ }^{-2} \mathrm{~s}^{-1}$ of RGB light for next $30 \mathrm{~min}$. The minimal fluorescence level (Fo) was measured by the measuring modulated blue light $(450 \mathrm{~nm})$, which was sufficiently low $\left(0.01 \mu \mathrm{mol} \mathrm{m} \mathrm{m}^{-2} \mathrm{~s}^{-1}\right)$ to not induce any significant variable fluorescence. The maximal fluorescence level $(\mathrm{Fm})$ was determined by a $0.8 \mathrm{~s}$ saturating blue light pulse $(\mathrm{SP}=450 \mathrm{~nm})$ at $5000 \mu \mathrm{mol} \mathrm{m}^{-2} \mathrm{~s}^{-1}$ in dark-adapted samples. The maximum PSII photochemical efficiency Fv/Fm was derived from that $(\mathrm{Fv} / \mathrm{Fm}=(\mathrm{Fm}-\mathrm{Fo}) / \mathrm{Fm})$. Each bar represents the average $\pm \mathrm{SD}$ of six independent measurements $(n=6)$. Different letters indicate significant differences between treatments $(p=0.05)$ with a Tukey's HSD.

The partitioning of excitation energy was then analyzed to assess the contribution of the mechanism of regulated energy quenching ( $\Phi N P Q)$ (Figure 6) and to distinguish it from that of non-regulated quenching $(\Phi N O)$ (Figure 7) and photochemistry yield (ФPSII) (Figure 5). The amplitude of the quantum yield of the regulated energy dissipation expressed as $\Phi N P Q$, was similar to that measured with NPQ. However, in water-incubated samples, the $\Phi N P Q$ rose to $0.54,0.77,0.57$, and 0.8 after $600 \mathrm{~s}$ of AL illumination in WL, RL, GL, and BL samples, respectively (Figure 6). We also noticed that the amplitude of $\Phi$ NPQ in WL reached a maximum after about $50 \mathrm{~s}$ and then partially relaxed to a lower value within $200 \mathrm{~s}$. Such relaxation, which might be attributed to the appearance of transient energydependent quenching $\left(\mathrm{qE}_{\mathrm{TR}}\right)$, was not observed in plants grown under monochromatic light, presumably due to the lower PPFD applied for their cultivation. Although DTT-fed leaves in all light treatments presented a suppressed $\Phi$ NPQ rise compared to control, the difference was less pronounced than in the NPQ analysis. Similarly, the positive effect of AsA feeding on $\Phi N P Q$ amplitude in GL samples was also mitigated compared to NPQ analysis.

As the fraction of absorbed light energy added up to unity the reduced $\Phi$ NPQ amplitude was related to concomitant $\Phi N O$ rise (Figure 7), reflecting the contribution of absorbed excitation energy used by neither photochemistry nor protective regulatory mechanisms. Thus, on the same timescale, the $\Phi N O$ values accounted for $25,23,43$, and $20 \%$ of energy quenching for WL, RL, GL, and BL samples, respectively (Figure 7). Consequently, during the induction phase in all plants grown under monochromatic light, the kinetics of ФPSII showed rapid inhibition (Figure 5) due to the saturating intensity of AL. In the case of WL plants, grown in higher PPFD, $\Phi$ PSI accounted for about $20 \%$ of light energy utilization. However, during the first $600 \mathrm{~s}$ of the relaxation phase, the $\Phi P S I I$ values were restored to $0.67,0.57,0.56$, and 0.70 for $\mathrm{WL}, \mathrm{RL}, \mathrm{GL}$, and BL, respectively. The lower rate of $\Phi P S I I$ with a concomitant higher $\Phi N O$ value during recovery in GL and RL leaves was related to the already decreased $\mathrm{Fv} / \mathrm{Fm}$, noted prior to the analysis of NPQ dynamics. 

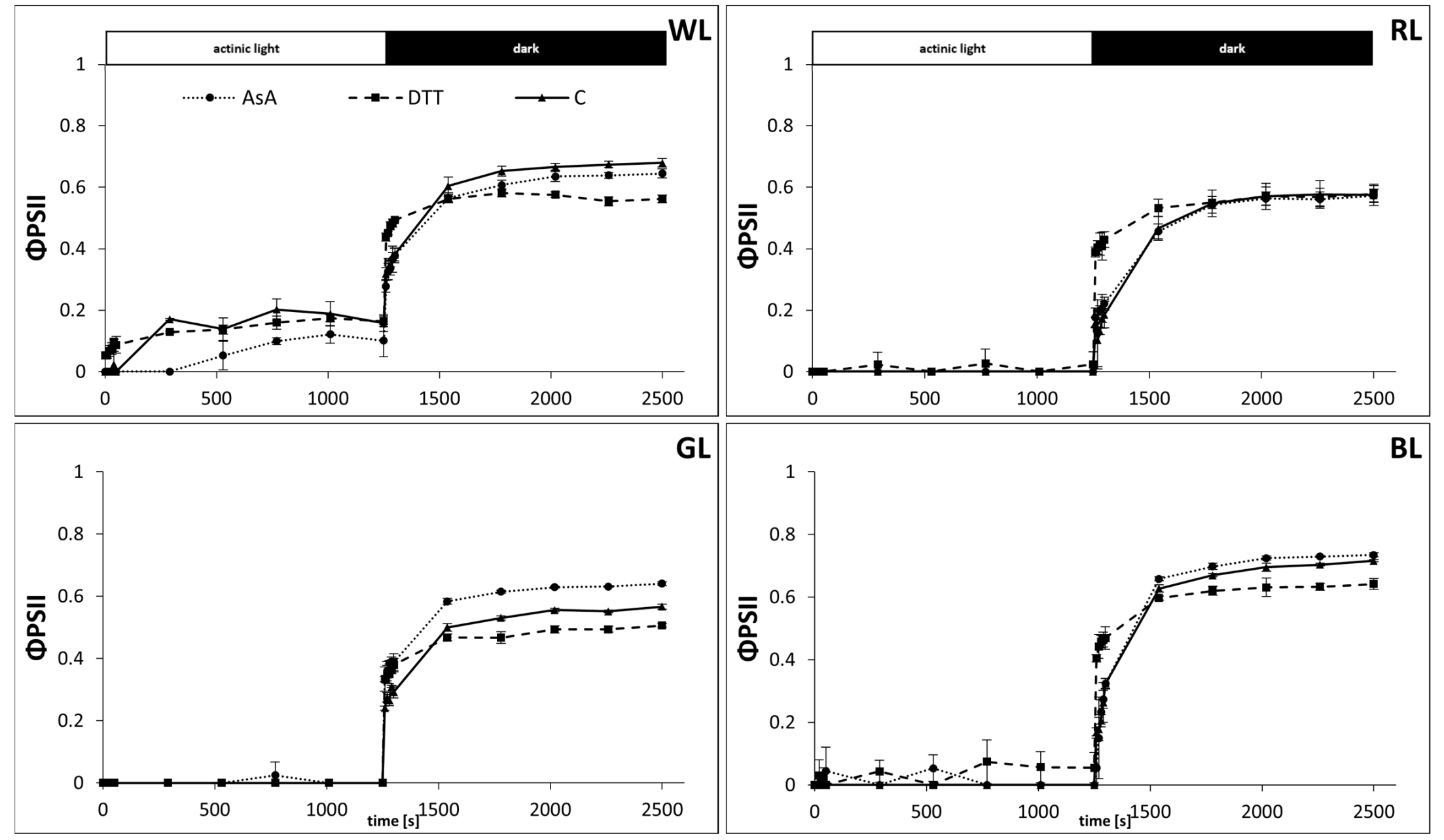

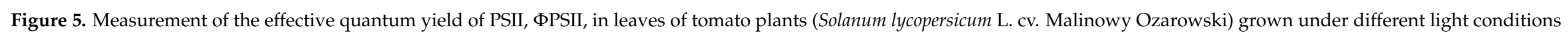

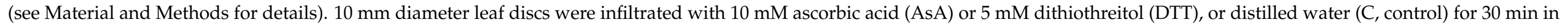

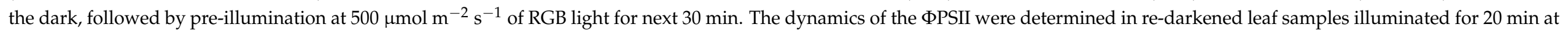

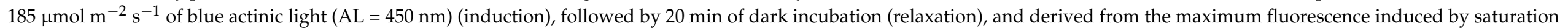
pulses $\left(5000 \mu \mathrm{mol} \mathrm{m}^{-2} \mathrm{~s}^{-1}, 0.8 \mathrm{~s}\right)$ at each of the measuring points $\left(\Phi P S I I=\left(\mathrm{Fm}^{\prime}-\mathrm{F}\right) / \mathrm{Fm}^{\prime}\right)$. Each data point represents the average $\pm \mathrm{SD}$ of six independent measurements $(n=6)$. 

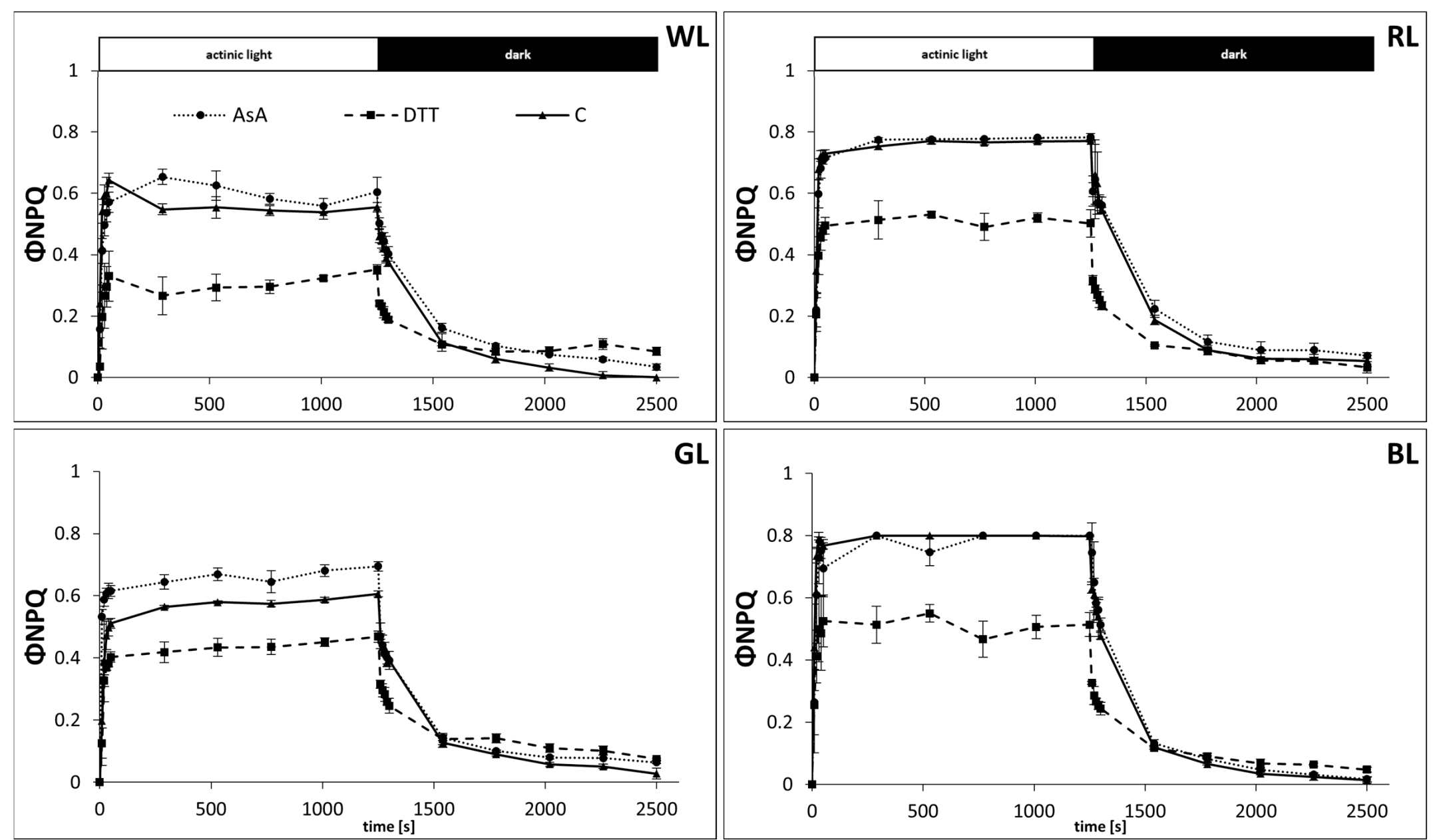

Figure 6. Measurement of the quantum yields of regulated energy dissipation, $\Phi \mathrm{NPQ}$, in leaves of tomato plants (Solanum lycopersicum L. cv. Malinowy Ozarowski) grown under different light conditions (see Material and Methods for details). $10 \mathrm{~mm}$ diameter leaf discs were infiltrated with $10 \mathrm{mM}$ ascorbic acid (AsA) or $5 \mathrm{mM}$ dithiothreitol (DTT), or distilled water (C, control) for $30 \mathrm{~min}$ in the dark, followed by pre-illumination at $500 \mu \mathrm{mol} \mathrm{m}{ }^{-2} \mathrm{~s}^{-1}$ of RGB light for next $30 \mathrm{~min}$. The dynamics of the $\Phi$ NPQ were determined in re-darkened leaf samples illuminated for $20 \mathrm{~min}$ at $185 \mu \mathrm{mol} \mathrm{m} \mathrm{m}^{-2} \mathrm{~s}^{-1}$ of blue actinic light $(\mathrm{AL}=450 \mathrm{~nm}$ ) (induction), followed by 20 min of dark incubation (relaxation), and derived from the maximum fluorescence induced by saturation pulses $\left(5000 \mu \mathrm{mol} \mathrm{m}{ }^{-2} \mathrm{~s}^{-1}, 0.8 \mathrm{~s}\right)$ at each of the measuring points $(\Phi \mathrm{NPQ}=1-\Phi \mathrm{PSII}-\Phi \mathrm{NO})$. Each data point represents the average $\pm \mathrm{SD}$ of six independent measurements $(n=6)$. 


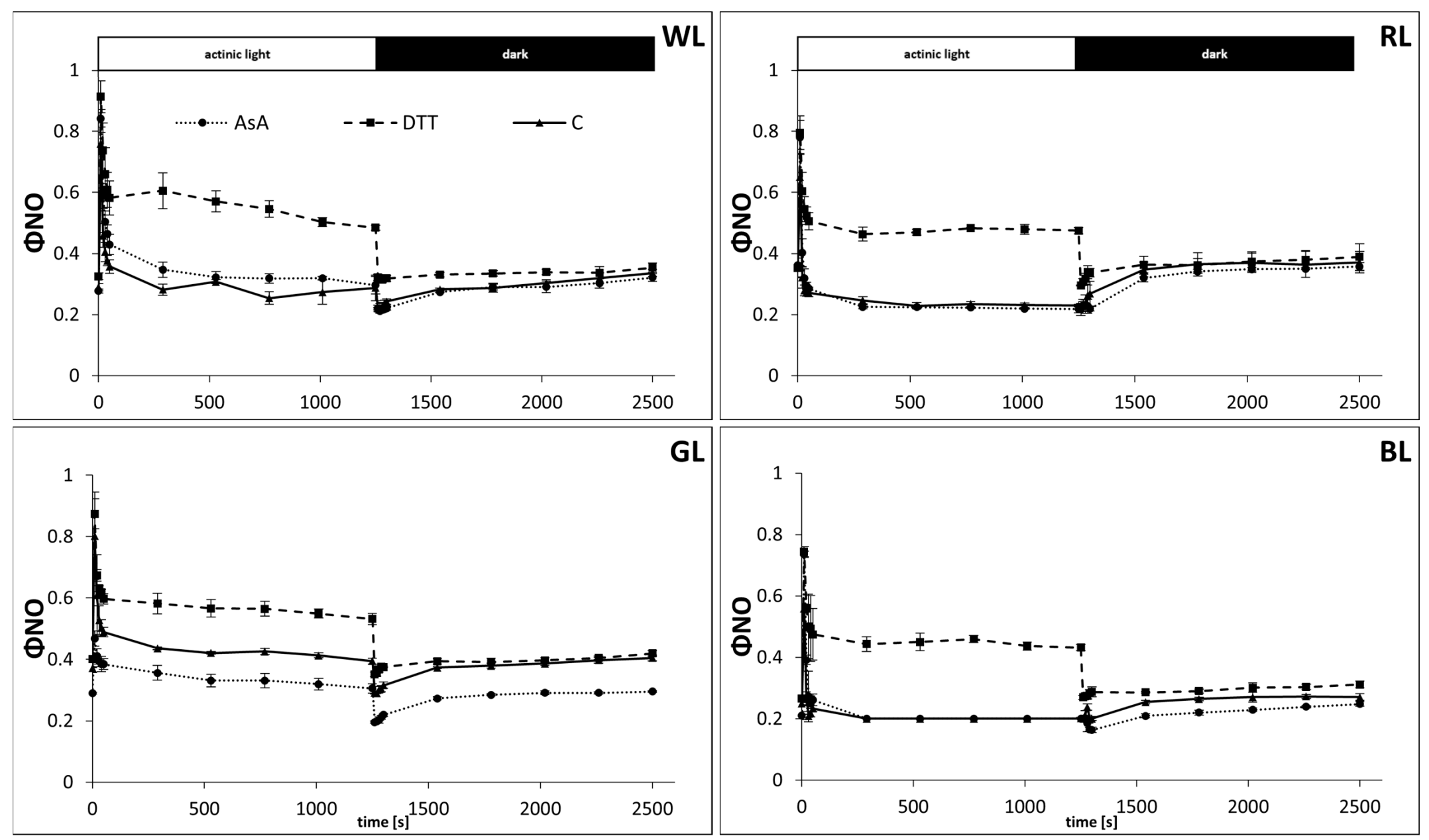

Figure 7. Measurement of the quantum yields of non-regulated energy dissipation in PSII, $\Phi$ NO, in leaves of tomato plants (Solanum lycopersicum L. cv. Malinowy Ozarowski) grown under different light conditions (see Material and Methods for details). $10 \mathrm{~mm}$ diameter leaf discs were infiltrated with $10 \mathrm{mM}$ ascorbic acid (AsA) or $5 \mathrm{mM}$ dithiothreitol (DTT), or distilled water (C, control) for $30 \mathrm{~min}$ in the dark, followed by pre-illumination at $500 \mu \mathrm{mol} \mathrm{m}^{-2} \mathrm{~s}^{-1}$ of RGB light for next $30 \mathrm{~min}$. The dynamics of the $\Phi N O$ were determined in re-darkened leaf samples illuminated for $20 \mathrm{~min}$ at $185 \mu \mathrm{mol} \mathrm{m} \mathrm{m} \mathrm{s}^{-1}$ of blue actinic light $(\mathrm{AL}=450 \mathrm{~nm}$ ) (induction), followed by $20 \mathrm{~min}$ of dark incubation (relaxation), and derived from the maximum fluorescence induced by saturation pulses $\left(5000 \mu \mathrm{mol} \mathrm{m}{ }^{-2} \mathrm{~s}^{-1}, 0.8 \mathrm{~s}\right)$ at each of the measuring points $[\Phi \mathrm{NO}=1 /(\mathrm{NPQ}+1+\mathrm{qL}(\mathrm{Fm} / \mathrm{Fo}-1))]$. Each data point represents the average $\pm \mathrm{SD}$ of six independent measurements $(n=6)$. 


\subsection{Photosynthetic Pigment Accumulation}

Decreased concentrations of chlorophyll $a$ and $b(\mathrm{Chl} a$ and $b$ ) were detected in leaves of the GL group, but the former only when compared to BL plants (Table 3). Consequently, cumulative chlorophyll concentration was lower in GL leaves than in WL and BL leaves by 13 and $15 \%$, respectively. Like GL plants, RL also presented a tendency for decreased content of both chlorophylls, however, there was no statistically significant difference compared to WL. Despite the differences in chlorophyll accumulation, spectrum quality did not affect the $\mathrm{Chl} a / b$ ratio. However, the content of carotenoids, which were estimated as a pool, was also found to be the lowest in GL plants (Table 3).

Table 3. The abundance of photosynthetic pigments extracted with DMSO from 3-mm leaf discs of tomato plants grown under different light conditions: WL-the R:G:B = 1:1:1 at $120 \mu \mathrm{mol} \mathrm{m}{ }^{-2} \mathrm{~s}^{-1}$; RL, GL or BL-monochromatic red (R), green (G) or blue (B) light (L) at $80 \mu \mathrm{mol} \mathrm{m}^{-2} \mathrm{~s}^{-1}$, respectively. The presented values are means of ten replicates \pm SD. Different letters in the same row indicate significant differences between treatments at $p=0.05$ with a Tukey's HSD test. Chl $a$-chlorophyll $a$, Chl $b$-chlorophyll $b$, FW-fresh weight.

\begin{tabular}{lcccc}
\hline \multicolumn{1}{c}{ Parameter } & \multicolumn{2}{c}{ Treatment } & GL & BL \\
\hline $\mathrm{Chl} a+b\left(\mathrm{mg} \mathrm{g}^{-1} \mathrm{FW}\right)$ & $2.77 \pm 0.19^{\mathrm{a}}$ & $2.62 \pm 0.23^{\mathrm{ab}}$ & $2.42 \pm 0.13^{\mathrm{b}}$ & $2.85 \pm 0.18^{\mathrm{a}}$ \\
\hline $\mathrm{Chl} a\left(\mathrm{mg} \mathrm{g}^{-1} \mathrm{FW}\right)$ & $2.18 \pm 0.20^{\mathrm{ab}}$ & $2.05 \pm 0.19^{\mathrm{ab}}$ & $1.91 \pm 0.16^{\mathrm{b}}$ & $2.27 \pm 0.19^{\mathrm{a}}$ \\
\hline $\mathrm{Chl} b\left(\mathrm{mg} \mathrm{g}^{-1} \mathrm{FW}\right)$ & $0.59 \pm 0.02^{\mathrm{a}}$ & $0.57 \pm 0.03^{\mathrm{a}}$ & $0.51 \pm 0.03^{\mathrm{b}}$ & $0.58 \pm 0.03^{\mathrm{a}}$ \\
\hline $\mathrm{Chl} a / b$ & $3.69 \pm 0.44^{\mathrm{a}}$ & $3.60 \pm 0.37^{\mathrm{a}}$ & $3.75 \pm 0.48^{\mathrm{a}}$ & $3.91 \pm 0.46^{\mathrm{a}}$ \\
\hline Carotenoids $\left(\mathrm{mg} \mathrm{g}^{-1} \mathrm{FW}\right)$ & $0.44 \pm 0.03^{\mathrm{a}}$ & $0.42 \pm 0.03^{\mathrm{a}}$ & $0.37 \pm 0.02^{\mathrm{b}}$ & $0.43 \pm 0.03^{\mathrm{a}}$ \\
\hline
\end{tabular}

\subsection{Activity of Antioxidant Enzymes APX, SOD, and CAT; MDA Accumulation}

The activity levels of antioxidant enzymes in tomato leaves are presented in Figure 8. APX activity in the GL treatment was about 25\% higher than that in the WL treatment. However, in other groups, APX activity declined by approximately 38 and 15\% under RL and BL, respectively (Figure 8a). Monochromatic green light also showed a positive effect on SOD in relation to other treatments, presenting 39\% higher activity compared to WL plants (Figure $8 b$ ). At the same time, there was no significant difference in SOD activity between RL and BL treatments; however, SOD activity was still about 17 and 24\% lower under RL and BL, respectively, than under WL. Thus, an increase in SOD activity in WL indicates that GL supplementation led to a concomitant stimulation of antioxidant properties. At the same time, no statistically significant differences were found in CAT activity among light treatments (Figure 8c). However, we noticed that light quality affected MDA accumulation, related to the rate of lipid peroxidation in the leaf tissue. Consequently, the highest MDA levels were noticed in leaves developed under GL and RL, and were about 21 and $9 \%$ higher than under WL, while under BL the MDA accumulation decreased by $15 \%$ (Figure $8 d$ ). 


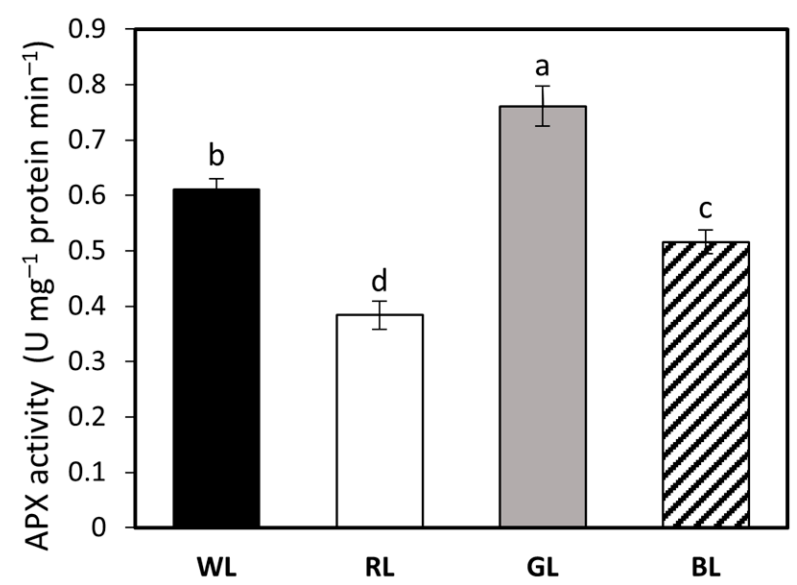

(a)

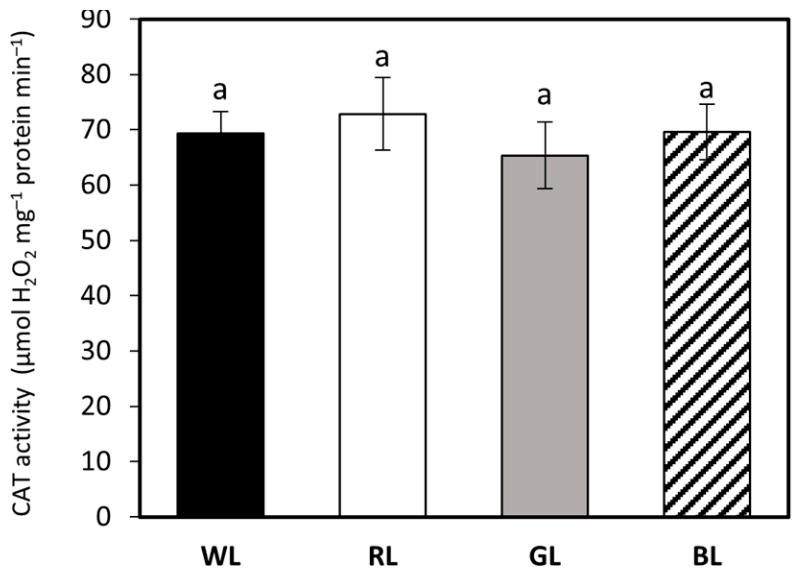

(c)

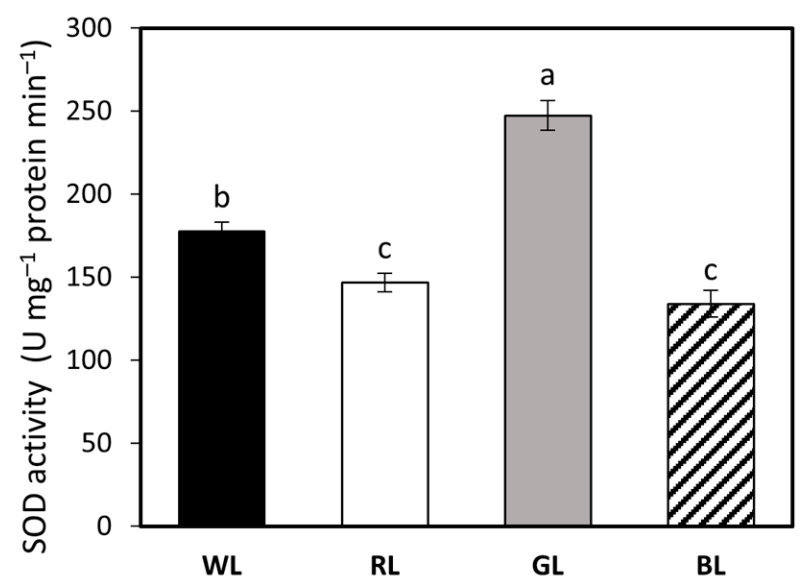

(b)

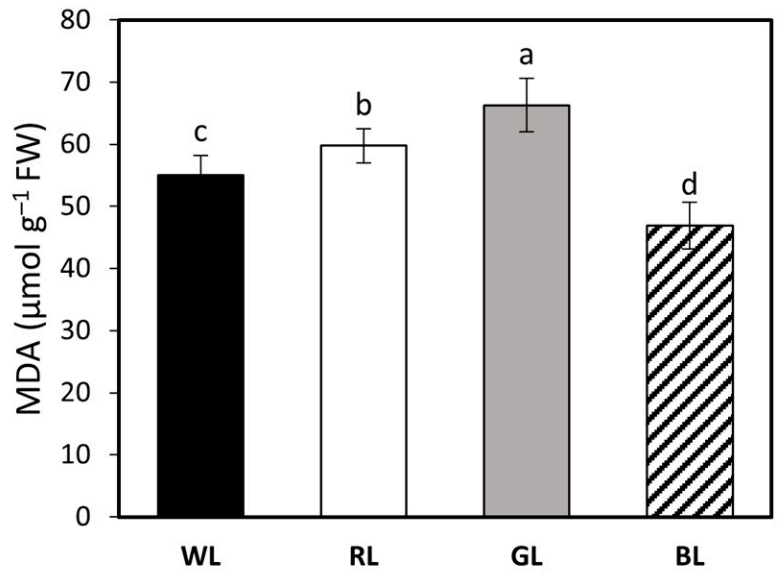

(d)

Figure 8. Ascorbate peroxidase (APX, a), superoxide dismutase (SOD, b) and catalase (CAT, c) enzyme activity levels, and malondialdehyde (MDA, d) accumulation in leaves of tomato plants (Solanum lycopersicum L. cv. Malinowy Ozarowski) grown under different light conditions (see Material and Methods for details). Bars show the means $\pm \operatorname{SD}(n=4)$. Different letters indicate significant differences between treatments $(p=0.05)$ with a Tukey's HSD test. U—unit of enzyme activity. FW-fresh weight.

\subsection{Accumulation of Leaf Proteins Related to NPQ}

The immunoblot analysis demonstrated that light quality changed the accumulation patterns of analyzed proteins. As shown in Figure 9, plants that were grown under monochromatic red and blue light showed increased levels of PsbS protein by about 48 and $89 \%$, respectively, while the lowest content of PsbS was recorded in plants grown under GL (reduced by 20\%) with respect to WL (Figure 9a,b, Figure S1). In addition, VDE accumulation was 34 and 50\% higher in RL and BL plants than in control plants. In contrast, there was a 15\% decrease in VDE content in GL-grown leaves (Figure 9a,c, Figure S2).

Additionally, no significant differences in PGRL1 concentrations were observed between leaves of RL- and BL-grown tomato plants, but the protein level was still 11\% higher than in WL plants (Figure 9a,d, Figure S2). The lowest level of PGRL1 protein was again found in GL plants, with a decrease of nearly $8 \%$. The plants grown under RL and BL showed approximately $10 \%$ higher cyt $f$ accumulation than plants grown under the mixed spectrum, while plants grown under GL showed a 30\% decrease in cytochrome subunit concentration (Figure 9a,e, Figure S3). 


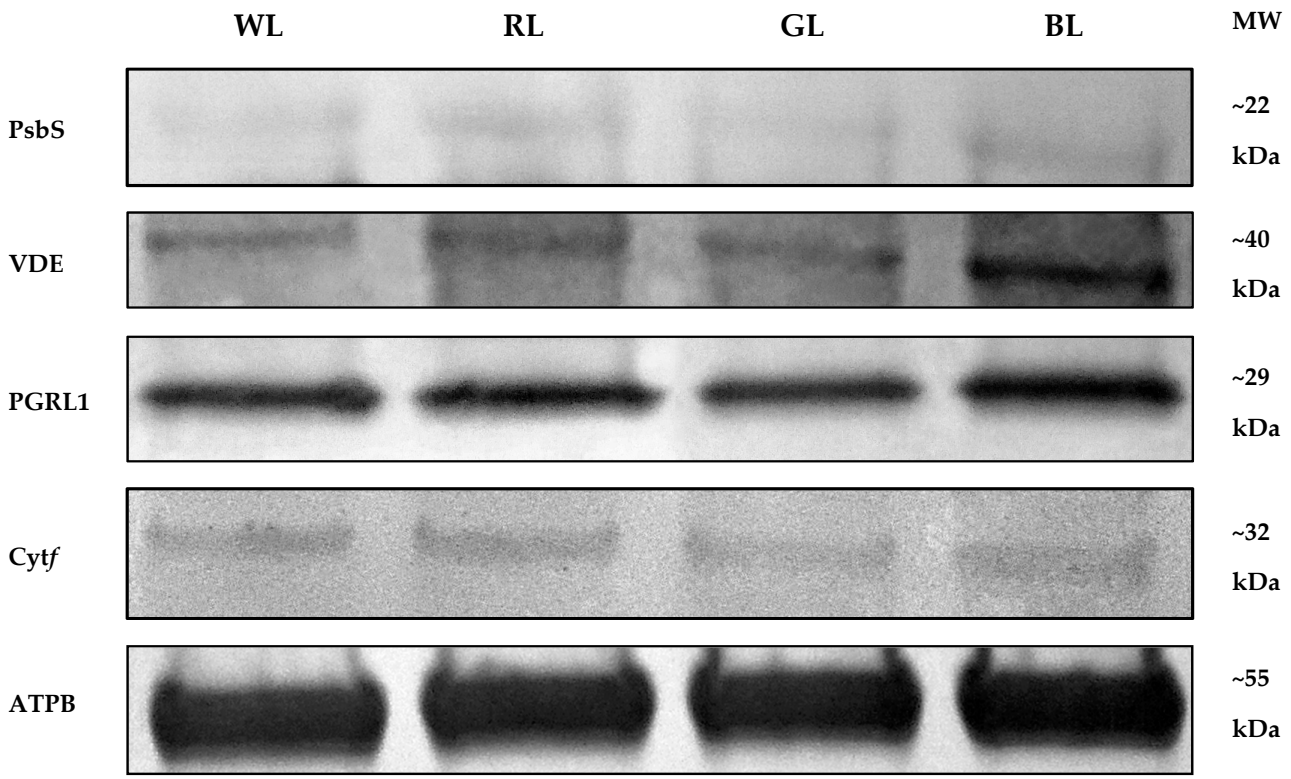

(a)
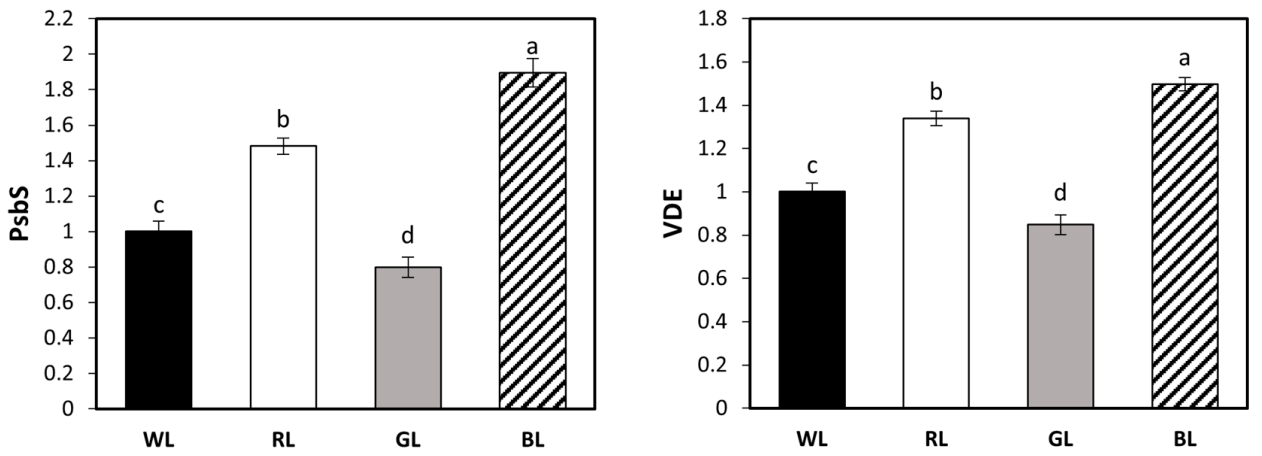

(b)

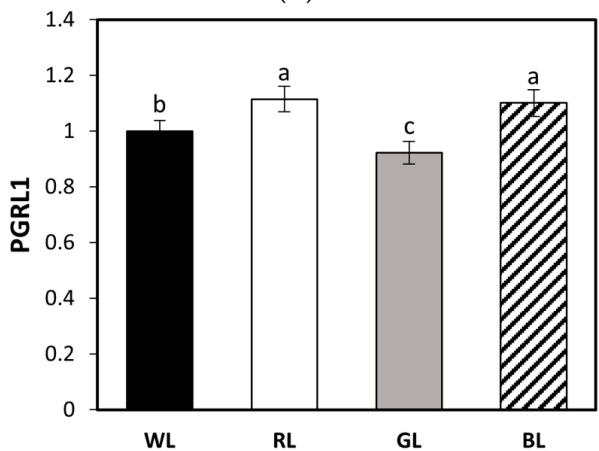

(d)

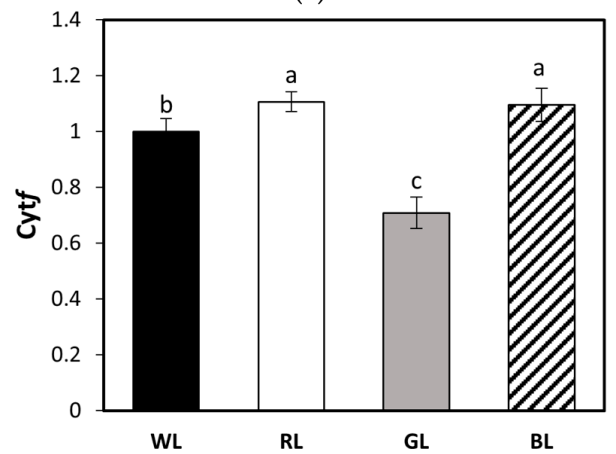

(e)

Figure 9. Western Blot analyses (a) and densitometric analyses of PsbS (b), VDE (c), PGRL1 (d), and cyt $f$ (e) proteins in leaves of tomato plants (Solanum lycopersicum L. cv. Malinowy Ozarowski) grown under different light conditions (see Material and Methods for details). The bands were normalized to the appropriate $\beta$ subunit of ATP synthase (ATPB) band (loading control, Figure S4) (a). The bar diagrams (b-e) represent pixel volumes (densitometric analyses) of proteins in samples. Each value represents the mean $\pm \mathrm{SD}(n=3)$ considering the control sample (WL) value as $1(100 \%)$. Different letters indicate significant differences between treatments $(p=0.05)$ with a Tukey's HSD test. MW-molecular weight. 


\section{Discussion}

\subsection{Photosynthetic Capacity under Different Type of Light Quality}

As compared to WL, there was a significant decrease in Fv/Fm value in RL- and GLgrown plants, while BL improved the maximum PSII photochemical efficiency. However, in all light treatments, the Fv/Fm value did not exceed the 0.8 value, which can be, at least partially, caused by increased light intensity applied during the pre-illumination of darkadapted plants [26]. Authors of [26] documented that for plants grown at $150 \mu \mathrm{mol} \mathrm{m}{ }^{-2} \mathrm{~s}^{-1}$ reduction of $\mathrm{Fv} / \mathrm{Fm}$ was detectable when applied more than $300 \mu \mathrm{mol} \mathrm{m}^{-2} \mathrm{~s}^{-1}$, and pronounced when applied $>1000 \mu \mathrm{mol} \mathrm{m}^{-2} \mathrm{~s}^{-1}$ of light during the pre-illumination. Thus, since we have grown plants under lower PPFD, the light intensity of $500 \mu \mathrm{mol} \mathrm{m}{ }^{-2} \mathrm{~s}^{-1}$ could, in fact, reduce the maximum photochemical efficiency of PSII in all analyzed groups. However, this approach allowed us to overcome the limitation of NPQ formation by the rate of $Z$ synthesis and activation of photosynthetic electron transport [26].

At the same time, the effective quantum yield of PSII photochemistry (ФPSII) measured during the dark recovery was higher in WL and BL plants, while $\Phi N O$ was lower in these plants, compared to RL and GL. This might indicate a sort of photoinactivation in PSII in RL and GL plants after exposition to high-intensity light due to photoprotective mechanisms impairment [29]. However, while the $\Phi N P Q$ was indeed lower in GL, its amplitude in RL was significantly increased compared to WL. Moreover, analyzed dynamics of $\Phi N O$ in water-incubated leaves of all light treatments (Figure 7) indicate the relative stability of its value during measurement, which results from compensatory changes in $\Phi P S I I$ (Figure 5) and $\Phi N P Q$ (Figure 6). This is because the sum of all yields for dissipative processes is unity [29]. Whereas, the observed discrepancies of $\Phi N O$ amplitude among the light treatments, likely arise from the concomitant competing activity of $\Phi$ NPQ positively correlated to the level of PsbS protein accumulation [29].

Therefore, to elucidate the mechanism by which monochromatic red and green light reduced the photochemical efficiency we also analyzed chlorophyll $a$ and $b$ and carotenoids accumulation. Analysis showed, however, that among the monochromatic lights, only green exerted a significant negative influence on pigment accumulation, while the effect of RL was not statistically significant. The highest chlorophyll accumulation was noticed for BL plants. Consequently, as the WL spectrum is composed of individual R-, G- and BLEDs, we conclude that the observed improvement in photochemical activity and pigment accumulation in WL was mostly related to the contribution of blue light in the spectrum. Additionally, the increased concentrations of cyt $f$ and PGRL1 proteins documented in monochromatic BL and RL indicate that the rates of electron transfer under BL and RL were significantly higher than in GL and even more enhanced than under mixed RGB spectrum. Previously, the authors of [17] documented that, in rice seedlings exposed to monochromatic R, G, or B light, the Fv /Fm levels were the same as in WL. However, rice grown in red or green LED showed low efficiency of photochemical utilization of absorbed light energy, as indicated by decreased ФPSII [17]. It was also proved [41] that an increasing percentage of BL in the RB spectrum substantially increased both Fv/Fm and $\Phi P S I$, while leaves developed under monochromatic $\mathrm{R}$ light presented suboptimal $\mathrm{Fv} / \mathrm{Fm}$ value.

Interestingly, we found that infiltration of leaf samples with ascorbate prior to preillumination increased Fv/Fm in GL and BL plants, compared to water control and improved $\Phi$ PSII recovery during relaxation in GL-grown plants. In contrast, DTT-fed leaves of WL, GL, and BL plants showed decreased Fv/Fm and restricted $\Phi P S I I$ recovery. According to previous research [42], AsA plays a critical role in protecting the photosynthetic apparatus from high light damage. It has been documented [43] that ascorbate-fed leaves showed a smaller decrease and that dithiothreitol-fed leaves showed a greater decrease in $\mathrm{Fv} / \mathrm{Fm}$ in response to stress conditions. Thus, it seems that feeding ascorbate to GL leaves ameliorated the PSII photodamage during the pre-illumination phase due to increased $\Phi N P Q$ along with restriction of non-regulated energy dissipation, $\Phi N O$. This implies that GL-grown plants might suffer from restricted availability of reduced ascorbate, especially as the AsA used for leaf-feeding exist mainly in its reduced, active status [43]. 


\subsection{Effect of Light Quality on qE NPQ Component}

Previous analyses [17] documented that blue LED treatment increased and that red and green treatments decreased the NPQ levels compared to white LED treatment. Consistent with this, we provide evidence that growth light quality alters the kinetics and amplitude of the rapidly reversible non-photochemical quenching component, qE. The more rapid kinetics of the fast phase of NPQ induction and relaxation is related to the increased level of PsbS protein [2]. Moreover, as the active form of PsbS is triggered by a low lumen $\mathrm{pH}$ we also analyzed cytochrome $b_{6} f$ subunit $\mathrm{f}(\mathrm{cyt} f)$ and the PGR5/PGRL1 complex subunit PGRL1. cyt $b_{6} f$ occupies a central position in photosynthetic electron transport in LET and CET and determines the rate of protons translocation from the stroma to the lumen via the Q-cycle [44]. PGRL1, a transmembrane protein present in thylakoids and coupled with PGR5 protein [45], mediates the main CET pathway [46], that moves $\mathrm{H}^{+}$into the thylakoid lumen via the Q-cycle $[10,47]$.

Most interestingly, we found that BL-developed leaves and, to a lesser extent, RL leaves, presented significantly increased levels of PsbS, cytf, and PGRL1, compared to $\mathrm{WL}$. At the same time, plants grown under monochromatic green light or mixed redgreen-blue spectrum had significantly diminished levels of PsbS, cytf, and PGRL1 protein. The importance of the PsbS and PGR5/PGRL1 complex in NPQ activation was previously documented with $n p q 4$ and $p g r 5$ (also pgr1) mutants, which are defective in PsbS-dependent NPQ and proton influx from the stroma to the lumen [48], respectively. Several authors $[7,26,47-49]$ have documented that accelerated NPQ formation induced by pre-illumination was absent in npq4, which presented almost no NPQ formation, while in the pgr1 mutant, the NPQ rise was visibly slowed down and sensitive to DTT feeding [26]. On the other hand, another study [2] documented that Arabidopsis thaliana line L17, which overexpresses PsbS, presented an increased amplitude of rapidly reversible quenching and recovery. As the rapid turn-off of $\mathrm{qE}$ is also related to PsbS protein [50], the increased PsbS accumulation noticed in BL and RL plants may enhance the kinetics of both the onset and recovery of NPQ.

Thus, it might be speculated that a lower amplitude and a slower rate of NPQ formation in GL and WL are predominantly due to a decreased PsbS level and a reduced rate of $\Delta \mathrm{pH}$ formation. In contrast to previous analysis [26], however, we found that DTT infiltration was less effective in preventing rapid NPQ induction in GL plants (35\%), compared to WL (67\%), BL (64\%), or RL (63\%). Moreover, as the AsA feeding in GL leaves significantly induced $\mathrm{qE}$, we speculate that the reduced rate of qE NPQ observed in GL is a consequence of the combination of reduced PsbS and decreased VDE activity rather than depressed $\mathrm{pH}$ gradient formation. Another study [51] also employed DTT feeding to gain insight into the role of $Z$ in fast NPQ induction and proved that $Z$ formation during pre-illumination is implicated in qE modulation. It is widely accepted that $Z$ is required for the generation of maximum $q E$, whereas the amount of $Z$ needed for such activation is rather low [26]. The authors of [26] defined such process as transient $\mathrm{qE}$ ( $\mathrm{qE}_{\mathrm{TR}}$ ) and noted that $\mathrm{qE}_{\mathrm{TR}}$ shows similar characteristics to $\mathrm{qE}$, while it depends on the presence of PsbS protein, transthylakoid $\mathrm{pH}$ gradient, and the amount of de-epoxidized xanthophylls. Moreover, other authors [7] proposed that $\mathrm{Z}$ can be considered as a kind of light stress memory in chloroplasts, allowing rapid reactivation of photoprotective NPQ processes. In our study, however, the different amplitude of the NPQ immediate response was related to growth light adaptations expressed in protein alterations, rather than the pre-illumination history. We found that monochromatic RL and, even more, the BL condition might, at some point, mimic the light stress conditions, enhancing the accumulation of NPQ-related proteins, consequently, presenting an enhanced NPQ response. An opposite trend was observed for GL- and WL-developed leaves, indicating the alleviating effect of the green component in the RGB spectrum on WL plants, despite the pre-illumination. 


\subsection{Effect of Light Quality on qZ NPQ Component}

In our study, the slower phase of NPQ induction was attributed to $\mathrm{qZ}$, as the incubation of leaves with DTT successfully eliminated the NPQ rise on the 50-600 s timescale compared to water-treated samples. Additionally, as the amplitude of qZ did not increase at longer illumination times (600-1250 s), the photoinhibitory NPQ component (qI) might be excluded [27]. Overall, the qZ phase of water-treated samples contributed about $16 \%$ of the total NPQ value in BL and about $24 \%$ in GL leaves. Thus, the effect of inhibited Z formation on $\mathrm{qZ}$ was less pronounced than observed for fast $\mathrm{qE}$ induction, which has the largest impact on the quenching rate. However, for the GL leaves, we found that AsA feeding also increased the amplitude of the $\mathrm{qZ}$ component. Therefore, it seems that $\mathrm{Z}$ synthesis was not completely abolished in GL samples, but rather significantly slowed down, and such an inhibition cannot be easily overcome by pre-illumination. It was suggested in [52] that light wavelengths are not equally effective in stimulating carotenoid de-epoxidation upon pre-illumination. That study documented that green light at low intensity was ineffective in inducing $Z$ synthesis, compared to $R$ light. Interestingly, even though pre-illumination in our study was conducted with an RGB light source, we observed decreased NPQ dynamics in leaves developed previously under monochromatic green or green-supplemented RGB spectrum. The most reasonable hypothesis, in this context, would seem to be that GL imposes an inactivation of $Z$ synthesis with VDE, which might be only partially rescued with AsA feeding. To solve this, we analyzed VDE accumulation and found the both GL and WL-grown leaves presented significantly lower enzyme levels compared to BL and RL. Similarly, other authors [17] have documented that rice seedlings grown under blue LEDs presented upregulated expression, and those grown under green and red LEDs presented unchanged expression of the VDE gene, compared to white LED.

Additionally, the kinetics of the middle phase of NPQ relaxation (1300-1540 s) seems to be partially attributable to the $\mathrm{Z}$ pool, as the rate of relaxation was substantially lower in the DTT-fed leaves than in the control condition. It has been reported [8] that DTT causes a strong dose-dependent decrease in the amplitude of NPQ dark relaxation due to its interference with the chloroplast redox state. The retardation of epoxidation kinetics in DTT samples might also be correlated with the decrease in PSII quantum efficiency [53] observed in WL, GL, and BL plants.

\subsection{Correlation between Antioxidant Activity, Lipid Peroxidation and Excitation Energy Quenching under Different Light Quality}

To further explain the way AsA infiltration stimulated NPQ of plants grown under different types of light quality, we analyzed the activity of the antioxidant enzymes. It has been reported [1] that the ascorbate limitation of VDE and NPQ that occurs under stress conditions is affected by APX activity. As AsA acts as an electron donor for both de-epoxidation of $\mathrm{V}$ and neutralization of chloroplastic $\mathrm{H}_{2} \mathrm{O}_{2}$, APX competes with VDE for the AsA pool [54]. Second, the way that light quality influences APX and other related antioxidant enzymes (such as SOD and CAT) has been previously analyzed $[16,17]$. Similar to previous reports [16,17], our results also indicate that spectrum quality has a rather minor influence on CAT activity. The authors of [16] concluded, however, that including GL in the RB spectrum increased the activity of APX and SOD, which can scavenge ROS, whereas others [17] have noticed that both monochromatic red and green light increase APX and SOD activity compared to white and blue light treatment. As an explanation, the latter authors [17] stated that GL- and RL-induced APX and SOD activity was due to insufficient energy dissipation through zeaxanthin and NPQ. Interestingly, we also noticed that increased APX and SOD activities in GL and WL leaves were related to a concomitant depressed NPQ amplitude. Similarly, the authors of [5] also documented that rice grown under blue or red light presented a compromised antioxidant system compared to white light, which contributed to increased NPQ amplitude. In contrast to the results of the previous study [17], however, we did not notice a stimulating influence of RL on antioxidant enzyme activity. 
Overall, our results suggest that the influence of monochromatic G, and, to a lesser extent, its addition to the RB spectrum is manifested in an increased demand for APX and SOD activity due to insufficient dissipative processes. Moreover, as we noticed increased MDA accumulation in GL- and RL-developed leaves, we speculate that both suffered from increased oxidative damage to chloroplast membranes caused by excessive ROS formation, in the way that has been previously reported [55]. These findings are not strictly concurrent with antioxidant activities pattern, explain, however, a concomitant decrease in Fv/Fm value in response to different light treatments. Previous authors [56] stated that the reduction in $\mathrm{Fv} / \mathrm{Fm}$ indicates that the plant is suffering from a suboptimal light environment and that disturbed ROS homeostasis induces antioxidant components and oxidative damage. Additionally, as a reduced Fv/Fm ratio means that the PSII activity already decreased in the initial process of photoseparation of charges in its reaction center [57], it might also explain the reduced photochemistry yield (ФPSII) value observed under monochromatic red and green light. As the authors of [57] revealed a critical role of various photoreceptors in the photosynthetic response of tomato plants to short-term light stress, an additional analysis of photoreceptors (e.g., phytochromes, cryptochromes) in plants grown under different light qualities is worthy of consideration for further study.

\section{Conclusions}

The results demonstrate that monochromatic red and blue light increased the kinetics and amplitude of NPQ compared to what was observed for GL- and WL-developed leaves. Moreover, the BL- and RL-developed leaves presented significantly increased levels of PsbS, cytf, and PGRL1, while the plants grown under monochromatic GL or mixed redgreen-blue spectrum had significantly diminished levels of accumulation. We also noticed that AsA feeding was able to stimulate NPQ and $\Phi$ NPQ in WL and GL leaves, which was associated with enhanced APX activity and decreased VDE activity in these plants. On the contrary, growing plants under RL or BL attenuated the APX and SOD (but not CAT) activity along with increased VDE activity. Interestingly, the effects of inhibited Z formation with DTT in pre-illuminated samples were more pronounced during rapid $\mathrm{qE}$ than $\mathrm{qZ}$ induction, indicating the importance of de-epoxidized xanthophylls during fast NPQ formation in light. Finally, we found that impairment of the photosynthetic apparatus was enhanced in plants exposed to monochromatic RL or GL, as evidenced by decreased photochemistry efficiency (Fv/Fm and $\Phi P S I I)$, increased MDA accumulation, and in GL plants also by decreased photosynthetic pigment levels. While the WL and BL-grown plants presented higher vitality of PSII and a lower rate of lipid peroxidation.

Supplementary Materials: The following are available online at https:/ /www.mdpi.com/article/10 $.3390 /$ biology10080721/s1, Figure S1: Western blot membrane of PsbS ( 22 kDa) protein detected with anti-PsbS (AS09 533; 1:1000; Agrisera, Vännäs, Sweden) antibody, Figure S2: Western blot membrane of VDE ( 40 kDa) and PGRL1 ( 29 kDa) protein detected with anti-VDE (AS15 3091; 1:1000; Agrisera) and anti-PGRL1 (AS10 725/AS19 4311; 1:1000; Agrisera) antibodies, respectively, Figure S3: Western blot membrane of cytf ( $\sim 2 \mathrm{kDa}$ ) protein detected with anti-cytf (AS08 306; 1:5000; Agrisera) antibody, Figure S4: Western blot membrane of ATPB ( $55 \mathrm{kDa})$ protein (loading control) detected with anti-ATPB (beta subunit of ATP synthase; AS05 085; 1:5000; Agrisera) antibody.

Author Contributions: Conceptualization, M.T. and E.S.; formal analysis, M.T. and E.S.; methodology, E.S.; data curation, M.T.; writing-original draft preparation, M.T. and E.S.; writing-review and editing, M.T. and E.S. All authors have read and agreed to the published version of the manuscript.

Funding: This research was funded by the Polish Ministry of Science and Higher Education (Grant No. 612078, M.T.) and the Polish National Science Centre (Grant No. UMO-2014/15/N/NZ9/01378, E.S.)

Institutional Review Board Statement: Not applicable.

Informed Consent Statement: Not applicable. 
Data Availability Statement: Data are available on request due to restrictions, e.g., privacy or ethics. The data presented in this study are available on request from the corresponding author. The data are not publicly available due to the strict management of various data and technical resources within the research teams.

Conflicts of Interest: The authors declare no conflict of interest.

\section{References}

1. Müller-Moulé, P.; Conklin, P.L.; Niyogi, K.K. Ascorbate deficiency can limit violaxanthin de-epoxidase activity in vivo. Plant Physiol. 2002, 128, 970-977. [CrossRef]

2. Steen, C.J.; Morris, J.M.; Short, A.H.; Niyogi, K.K.; Fleming, G.R. Complex roles of PsbS and xanthophylls in the regulation of nonphotochemical quenching in Arabidopsis thaliana under fluctuating light. J. Phys. Chem. B 2020, 124, 10311-10325. [CrossRef]

3. Malnoë, A. Photoinhibition or photoprotection of photosynthesis? Update on the (newly termed) sustained quenching component qH. Environ. Exp. Bot. 2018, 154, 123-133. [CrossRef]

4. Sukhova, E.; Khlopkov, A.; Vodeneev, V.; Sukhov, V. Simulation of a nonphotochemical quenching in plant leaf under different light intensities. Biochim. Biophys. Acta Bioenerg. 2020, 1861, 148138. [CrossRef]

5. Hamdani, S.; Khan, N.; Perveen, S.; Qu, M.; Jiang, J.; Zhu, X.G. Changes in the photosynthesis properties and photoprotection capacity in rice (Oryza sativa) grown under red, blue, or white light. Photosyn. Res. 2019, 139, 107-121. [CrossRef] [PubMed]

6. Nicol, L.; Croce, R. The PsbS protein and low $\mathrm{pH}$ are necessary and sufficient to induce quenching in the light-harvesting complex of plants LHCII. Sci. Rep. 2021, 11, 7415. [CrossRef] [PubMed]

7. Kress, E.; Jahns, P. The dynamics of energy dissipation and xanthophyll conversion in Arabidopsis indicate an indirect photoprotective role of zeaxanthin in slowly inducible and relaxing components of non-photochemical quenching of excitation energy. Front. Plant Sci. 2017, 8, 2094. [CrossRef]

8. Ferroni, L.; Colpo, A.; Baldisserotto, C.; Pancaldi, S. In an ancient vascular plant the intermediate relaxing component of NPQ depends on a reduced stroma: Evidence from dithiothreitol treatment. J. Photochem. Photobiol. B Biol. 2021, 215, 112114. [CrossRef]

9. Kohzuma, K.; Hikosaka, K. Physiological validation of photochemical reflectance index (PRI) as a photosynthetic parameter using Arabidopsis thaliana mutants. Biochem. Biophys. Res. Commun. 2018, 498, 52-57. [CrossRef]

10. Wang, F.; Yan, J.; Ahammed, G.J.; Wang, X.; Bu, X.; Xiang, H.; Li, Y.; Lu, J.; Liu, Y.; Qi, H.; et al. PGR5/PGRL1 and NDH mediate far-red light-induced photoprotection in response to chilling stress in tomato. Front. Plant Sci. 2020, 11, 669. [CrossRef] [PubMed]

11. Sun, L.N.; Wang, F.; Wang, J.W.; Sun, L.J.; Gao, W.R.; Song, X.S. Overexpression of the ChVDE gene, encoding a violaxanthin de-epoxidase, improves tolerance to drought and salt stress in transgenic Arabidopsis. 3 Biotech 2019, 9, 197. [CrossRef] [PubMed]

12. Arnoux, P.; Morosinotto, T.; Saga, G.; Bassi, R.; Pignol, D. A structural basis for the pH-dependent xanthophyll cycle in Arabidopsis thaliana. Plant Cell 2009, 21, 2036-2044. [CrossRef] [PubMed]

13. Jahns, P.; Holzwarth, A.R. The role of the xanthophyll cycle and of lutein in photoprotection of photosystem II. Biochim. Biophys. Acta Bioenerg. 2012, 1817, 182-193. [CrossRef] [PubMed]

14. Acebron, K.; Matsubara, S.; Jedmowski, C.; Emin, D.; Muller, O.; Rascher, U. Diurnal dynamics of nonphotochemical quenching in Arabidopsis npq mutants assessed by solar-induced fluorescence and reflectance measurements in the field. New Phytol. 2021, 229, 2104-2119. [CrossRef] [PubMed]

15. Ware, M.A.; Belgio, E.; Ruban, A.V. Comparison of the protective effectiveness of NPQ in Arabidopsis plants deficient in PsbS protein and zeaxanthin. J. Exp. Bot. 2015, 66, 1259-1270. [CrossRef]

16. Bian, Z.; Yang, Q.; Li, T.; Cheng, R.; Barnett, Y.; Lu, C. Study of the beneficial effects of green light on lettuce grown under short-term continuous red and blue light-emitting diodes. Physiol. Plant. 2018, 164, 226-240. [CrossRef] [PubMed]

17. Tran, L.H.; Lee, D.G.; Jung, S. Light quality-dependent regulation of photoprotection and antioxidant properties in rice seedlings grown under different light-emitting diodes. Photosynthetica 2021, 59, 12-22. [CrossRef]

18. Hallin, E.I.; Hasan, M.; Guo, K.; Åkerlund, H.E. Molecular studies on structural changes and oligomerisation of violaxanthin de-epoxidase associated with the $\mathrm{pH}$-dependent activation. Photosyn. Res. 2016, 129, 29-41. [CrossRef]

19. Sofo, A.; Scopa, A.; Nuzzaci, M.; Vitti, A. Ascorbate peroxidase and catalase activities and their genetic regulation in plants subjected to drought and salinity stresses. Int. J. Mol. Sci. 2015, 16, 13561-13578. [CrossRef]

20. Jahns, P.; Latowski, D.; Strzalka, K. Mechanism and regulation of the violaxanthin cycle: The role of antenna proteins and membrane lipids. Biochim. Biophys. Acta Bioenerg. 2009, 1787, 3-14. [CrossRef]

21. Murchie, E.H.; Ruban, A.V. Dynamic non-photochemical quenching in plants: From molecular mechanism to productivity. Plant J. 2020, 101, 885-896. [CrossRef]

22. Nishio, J.N. Why are higher plants green? Evolution of the higher plant photosynthetic pigment complement. Plant Cell Environ. 2000, 23, 539-548. [CrossRef]

23. Busch, B.L.; Schmitz, G.; Rossmann, S.; Piron, F.; Ding, J.; Bendahmane, A.; Theres, K. Shoot branching and leaf dissection in tomato are regulated by homologous gene modules. Plant Cell 2011, 23, 3595-3609. [CrossRef] [PubMed]

24. Pinnola, A.; Dall'Osto, L.; Gerotto, C.; Morosinotto, T.; Bassi, R.; Alboresi, A. Zeaxanthin binds to light-harvesting complex stress-related protein to enhance nonphotochemical quenching in Physcomitrella patens. Plant Cell 2013, 25, 3519-3534. [CrossRef] [PubMed] 
25. Anielska-Mazur, A.; Bernaś, T.; Gabryś, H. In vivo reorganization of the actin cytoskeleton in leaves of Nicotiana tabacum L. transformed with plastin-GFP. Correlation with light-activated chloroplast responses. BMC Plant Biol. 2009, 9, 64. [CrossRef]

26. Kalituho, L.; Beran, K.C.; Jahns, P. The transiently generated nonphotochemical quenching of excitation energy in Arabidopsis leaves is modulated by zeaxanthin. Plant Physiol. 2007, 143, 1861-1870. [CrossRef] [PubMed]

27. Nilkens, M.; Kress, E.; Lambrev, P.; Miloslavina, Y.; Müller, M.; Holzwarth, A.R.; Jahns, P. Identification of a slowly inducible zeaxanthin-dependent component of non-photochemical quenching of chlorophyll fluorescence generated under steady-state conditions in Arabidopsis. Biochim. Biophys. Acta Bioenerg. 2010, 1797, 466-475. [CrossRef] [PubMed]

28. Genty, B.; Briantais, J.M.; Baker, N.R. The relationship between the quantum yield of photosynthetic electron transport and quenching of chlorophyll fluorescence. Biochim. Biophys. Acta Gen. Subj. 1989, 990, 87-92. [CrossRef]

29. Kramer, D.M.; Johnson, G.; Kiirats, O.; Edwards, G.E. New fluorescence parameters for the determination of QA redox state and excitation energy fluxes. Photosyn. Res. 2004, 79, 209-218. [CrossRef]

30. Nakano, Y.; Asada, K. Hydrogen peroxide is scavenged by ascorbate-specific peroxidase in spinach chloroplasts. Plant Cell Physiol. 1981, 22, 867-880. [CrossRef]

31. Duan, B.; Yang, Y.; Lu, Y.; Korpelainen, H.; Berninger, F.; Li, C. Interactions between water deficit, ABA, and provenances in Picea asperata. J. Exp. Bot. 2007, 58, 3025-3036. [CrossRef]

32. Xu, P.L.; Guo, Y.K.; Bai, J.G.; Shang, L.; Wang, X.J. Effects of long-term chilling on ultrastructure and antioxidant activity in leaves of two cucumber cultivars under low light. Physiol. Plant 2008, 132, 467-478. [CrossRef] [PubMed]

33. Sarker, U.; Oba, S. Catalase, superoxide dismutase and ascorbate-glutathione cycle enzymes confer drought tolerance of Amaranthus tricolor. Sci. Rep. 2018, 8, 16496. [CrossRef]

34. Skowron, E.; Trojak, M. Effect of exogenously-applied abscisic acid, putrescine and hydrogen peroxide on drought tolerance of barley. Biologia 2021, 76, 453-468. [CrossRef]

35. Pilarska, M.; Wiciarz, M.; Jajić, I.; Kozieradzka-Kiszkurno, M.; Dobrev, P.; Vanková, R.; Niewiadomska, E. A different pattern of production and scavenging of reactive oxygen species in halophytic Eutrema salsugineum (Thellungiella salsuginea) plants in comparison to Arabidopsis thaliana and its relation to salt stress signaling. Front. Plant Sci. 2016, 7, 1179. [CrossRef] [PubMed]

36. Ying, Y.Q.; Song, L.L.; Jacobs, D.F.; Mei, L.; Liu, P.; Jin, S.H.; Wu, J.S. Physiological response to drought stress in Camptotheca acuminata seedlings from two provenances. Front. Plant Sci. 2015, 6, 361. [CrossRef] [PubMed]

37. Wellburn, A.R. The spectral determination of chlorophylls $a$ and $b$, as well as total carotenoids, using various solvents with spectrophotometers of different resolution. J. Plant Physiol. 1994, 144, 307-313. [CrossRef]

38. Bradford, M.M. A rapid and sensitive method for the quantitation of microgram quantities of protein utilizing the principle of protein-dye binding. Anal. Biochem. 1976, 72, 248-254. [CrossRef]

39. Tercé-Laforgue, T.; Mäck, G.; Hirel, B. New insights towards the function of glutamate dehydrogenase revealed during sourcesink transition of tobacco (Nicotiana tabacum) plants grown under different nitrogen regimes. Physiol. Plant 2004, 120, 220-228. [CrossRef]

40. Murchie, E.H.; Lawson, T. Chlorophyll fluorescence analysis: A guide to good practice and understanding some new applications. J. Exp. Bot. 2013, 64, 3983-3998. [CrossRef] [PubMed]

41. Hogewoning, S.W.; Trouwborst, G.; Maljaars, H.; Poorter, H.; van Ieperen, W.; Harbinson, J. Blue light dose-Responses of leaf photosynthesis, morphology, and chemical composition of Cucumis sativus grown under different combinations of red and blue light. J. Exp. Bot. 2010, 61, 3107-3117. [CrossRef]

42. Zeng, L.D.; Li, M.; Chow, W.S.; Peng, C.L. Susceptibility of an ascorbate-deficient mutant of Arabidopsis to high-light stress. Photosynthetica 2018, 56, 427-432. [CrossRef]

43. Yin, Y.; Li, S.; Liao, W.; Lu, Q.; Wen, X.; Lu, C. Photosystem II photochemistry, photoinhibition, and the xanthophyll cycle in heat-stressed rice leaves. J. Plant Physiol. 2010, 167, 959-966. [CrossRef]

44. Ermakova, M.; Lopez-Calcagno, P.E.; Raines, C.A.; Furbank, R.T.; von Caemmerer, S. Overexpression of the rieske FeS protein of the cytochrome b6f complex increases $C_{4}$ photosynthesis in Setaria viridis. Commun. Biol. 2019, 2, 1-12. [CrossRef]

45. DalCorso, G.; Pesaresi, P.; Masiero, S.; Aseeva, E.; Schünemann, D.; Finazzi, G.; Joliot, P.; Barbato, R.; Leister, D. A complex containing PGRL1 and PGR5 is involved in the switch between linear and cyclic electron flow in Arabidopsis. Cell 2008, 132, 273-285. [CrossRef] [PubMed]

46. Nakano, H.; Yamamoto, H.; Shikanai, T. Contribution of NDH-dependent cyclic electron transport around photosystem I to the generation of proton motive force in the weak mutant allele of pgr5. Biochim. Biophys. Acta Bioenerg. 2019, 1860, 369-374. [CrossRef] [PubMed]

47. Suorsa, M.; Rossi, F.; Tadini, L.; Labs, M.; Colombo, M.; Kater, M.M.; Leister, D.; Finazzi, G.; Aro, E.M.; Barbato, R.; et al. PGR5-PGRL1-dependent cyclic electron transport modulates linear electron transport rate in Arabidopsis thaliana. Mol. Plant 2016, 9, 271-288. [CrossRef]

48. Trinh, M.D.L.; Sato, R.; Masuda, S. Genetic characterization of a flap1 null mutation in Arabidopsis npq4 and pgr5 plants suggests that the regulatory role of FLAP1 involves the control of proton homeostasis in chloroplasts. Photosynth. Res. 2019, 139, $413-424$. [CrossRef] [PubMed]

49. Munekage, Y.; Hojo, M.; Meurer, J.; Endo, T.; Tasaka, M.; Shikanai, T. PGR5 is involved in cyclic electron flow around photosystem I and is essential for photoprotection in Arabidopsis. Cell 2002, 110, 361-371. [CrossRef] 
50. Zaks, J.; Amarnath, K.; Kramer, D.M.; Niyogi, K.K.; Fleming, G.R. A kinetic model of rapidly reversible nonphotochemical quenching. Proc. Natl. Acad. Sci. USA 2012, 109, 15757-15762. [CrossRef]

51. Essemine, J.; Govindachary, S.; Joly, D.; Ammar, S.; Bouzid, S.; Carpentier, R. Effect of moderate and high light on photosystem II function in Arabidopsis thaliana depleted in digalactosyl-diacylglycerol. Biochim. Biophys. Acta Bioenerg. 2012, 1817, 1367-1373. [CrossRef]

52. Finazzi, G.; Johnson, G.N.; Dallosto, L.; Joliot, P.; Wollman, F.A.; Bassi, R. A zeaxanthin-independent nonphotochemical quenching mechanism localized in the photosystem II core complex. Proc. Natl. Acad. Sci. USA 2004, 101, 12375-12380. [CrossRef] [PubMed]

53. Reinhold, C.; Niczyporuk, S.; Beran, K.C.; Jahns, P. Short-term down-regulation of zeaxanthin epoxidation in Arabidopsis thaliana in response to photo-oxidative stress conditions. Biochim. Biophys. Acta Bioenerg. 2008, 1777, 462-469. [CrossRef] [PubMed]

54. Akram, N.A.; Shafiq, F.; Ashraf, M. Ascorbic acid-a potential oxidant scavenger and its role in plant development and abiotic stress tolerance. Front. Plant Sci. 2017, 8, 613. [CrossRef]

55. Liu, Y.; Wang, T.; Fang, S.; Zhou, M.; Qin, J. Responses of morphology, gas exchange, photochemical activity of photosystem II, and antioxidant balance in Cyclocarya paliurus to light spectra. Front. Plant Sci. 2018, 9, 1704. [CrossRef]

56. Liu, X.; Chen, Z.; Jahan, M.S.; Wen, Y.; Yao, X.; Ding, H.; Guo, S.; Xu, Z. RNA-Seq analysis reveals the growth and photosynthetic responses of rapeseed (Brassica napus L.) under red and blue LEDs with supplemental yellow, green, or white light. Hortic. Res. 2020, 7, 206. [CrossRef] [PubMed]

57. Kreslavski, V.D.; Strokina, V.V.; Pashkovskiy, P.P.; Balakhnina, T.I.; Voloshin, R.A.; Alwasel, S.; Kosobryukhov, A.A.; Allakhverdiev, S.I. Deficiencies in phytochromes A and B and cryptochrome 1 affect the resistance of the photosynthetic apparatus to highintensity light in Solanum lycopersicum. J. Photochem. Photobiol. B 2020, 210, 111976. [CrossRef] [PubMed] 